\title{
Dietary Polyphenols Turn Fat "Brown": A Narrative Review of the Possible Mechanisms
} Jiamiao HU ${ }^{1,2 \#}$, Zhenyu WANG ${ }^{1 \#}$, Bee $\mathrm{K} \mathrm{TAN}^{3 *}$, Mark CHRISTIAN ${ }^{4 *}$

${ }^{1}$ College of Food Science, Fujian Agriculture and Forestry University, Fuzhou, 350002, P.R China

${ }^{2}$ Leicester Institute for Advanced Studies, University of Leicester, Leicester, LE1 7RH, United Kingdom

${ }^{3}$ Departments of Cardiovascular Sciences, Health Sciences and Leicester Diabetes Centre, College of Life Sciences, University of Leicester, Leicester, LE1 7RH, United Kingdom

${ }^{4}$ School of Science and Technology, Nottingham Trent University, Clifton, Nottingham, NG11 8NS, United Kingdom

\# contribute equally to the article

Corresponding authors: Prof Bee K Tan, email: bee.k.tan@leicester.ac.uk; Prof. Mark Christian, email: mark.christian@ntu.ac.uk

\begin{abstract}
:
Background

Inducible brown adipocytes called beige adipocytes are found in white adipose tissue (WAT) depots. They express functional UCP1 and have thermogenic fat-burning capacities as also found in classical brown adipocytes in response to various stimuli. Beige adipocytes may also secrete certain factors that affect WAT function and systemic metabolism. Therefore, a white-to-brown fat conversion could be a novel therapeutic avenue for tackling obesity and metabolic disorders.

Scope and Approach

In this review, we examine the evidence supporting the concept that the anti-obesity action attributed to polyphenols might be contributed by their stimulation of WAT browning, and discuss the possible underlying mechanisms involved in this action.

\section{Key Findings and Conclusions}

Current evidence, mostly derived from animal models, strongly supports that dietary polyphenols may play roles in the browning of WAT. Studies also show multiple signaling pathways, receptors, and transcription factors have been associated with the browning effects of dietary polyphenols. In conclusion, polyphenol compounds and their principal metabolites may contribute to counteracting human obesity via promoting WAT browning.
\end{abstract}

Keywords: Polyphenols; Beige adipocytes; Browning; Energy metabolism; Obesity 


\section{Introduction}

Obesity, which is accompanied by low-grade inflammation, insulin resistance, type 2 diabetes, hyperglycemia, hyperlipidemia, atherosclerosis, metabolic syndromes and decrease in life expectancy, has grown into a worldwide epidemic affecting large numbers of people (Engin, 2017). Current understanding indicates that the disruption of energy homeostasis leads to obesity (J. Gao, Ghibaudi, van Heek, \& Hwa, 2002; Hall et al., 2011). Adipose tissues with different color, morphology, metabolic function, biochemical characteristics and gene expression patterns exist in mammals (including humans and mice), and have been mainly divided into two types of fat, namely white adipose tissue (WAT) and brown adipose tissue (BAT) (Lidell et al., 2013; Rosell et al., 2014). An excess of energy is primarily stored in subcutaneous and visceral WAT. In the last decade, functional BAT, which contains a large number of mitochondria and expresses the BAT-specific gene uncoupling protein-1 (UCP1) to produce heat, was found in healthy adults. Moreover, after the classical BAT was identified in human adults (originating from myf5+ precursors), there is sufficient evidence to suggest the presence of brown-like (beige) adipocytes (originating from myf5precursors) in subcutaneous WAT depots, especially upon cold exposure or $\beta$-adrenergic stimulation (Table 1) (Cedikova et al., 2016; Park, Kim, \& Bae, 2014). Although classical BAT and beige adipose tissue (BeAT) share many similarities, they still exhibit differences in their morphology and functions (Kissig, Shapira, \& Seale, 2016), as illustrated in Figure 1. However, current evidence suggests that a number of the transcriptional regulators and coregulators that determine the differentiation of classic brown adipocytes are also key factors in the conversion of white adipocytes into beige adipocytes (beige adipogenesis) (Harms \& Seale, 2013; Kiskinis et al., 2014; W. Wang $\&$ Seale, 2016; Wu, Jun, \& McDermott, 2015). For example, key regulators of brown adipocyte differentiation including CCAAT-enhancer-binding protein $\beta(C / E B P \beta)$, PR domain-containing 16 (PRDM16), peroxisome proliferator-activated receptor $\gamma(P P A R \gamma)$, and peroxisome proliferatoractivated receptor gamma coactivator-1 alpha $(P G C l \alpha)$, were also identified as main targets for WAT transdifferentiation (Kajimura et al., 2009; Seale et al., 2007; Villanueva et al., 2013). PPAR $\gamma$ agonists or ectopic expression of $P G C 1 \alpha$ promotes adipose browning; while the ablation of $P R D M 16$ or $P G C 1 \alpha$ in white adipocytes inhibits formation and function of beige adipocytes (Ohno, Shinoda, Spiegelman, \& Kajimura, 2012; Tiraby et al., 2003; Seale et al., 2011; Kleiner et al., 2012). Meanwhile, PRDM16 can also repress white adipocyte specific genes through its association with C-terminal binding proteins (Kajimura et al., 2008). Moreover, hormones and cytokines such as noradrenaline (NA), bone morphogenetic protein 7 (BMP7) and fibroblast growth factor 21 (FGF21) also play key roles in inducing white-to-brown conversion (Hu \& Christian, 2017; Y. H. Lee, Jung, \& Choi, 2014; Wu et al., 2015) (Figure 1). Since the discovery of inducible beige adipocytes, modulation of adipose tissue browning to increase energy consumption, especially via dietary intervention, has become an attractive idea due to its promising application in obesity and metabolic diseases prevention and treatment (S. Wang et al., 2014). Indeed, beige adipocytes are functionally very similar to classical brown adipocytes upon various stimuli (such as cold exposure) and can contribute to energy expenditure through heat production, therefore, they are also categorized as thermogenic adipocytes (Scheja \& Heeren, 2016). The contribution of beige adipocytes to whole body energy balance is yet to be fully determined. However, mice with specific inactivation of beige adipocytes through ablation of PRDM16 (with minimal effects on classical BAT) become more obese and severely insulin resistant on a high fat diet (Cohen et al., 2014) clearly indicating an important role of these cells in whole-body energy homeostasis. 
Polyphenols are a class of secondary metabolite compounds widely present in plants (Z. Wang et al., 2019). Currently, there are over 8,000 identified polyphenols found in foods such as fruits, vegetables, tea, wine, chocolate, nuts, seeds, and even spices and seasonings (X. Z. Han, Shen, \& Lou, 2007). Polyphenols can be divided into four categories: flavonoids; phenolic acids; stilbenes and lignans (Figure 2). Aside from their well-known anti-oxidative functions, recent studies have suggested further mechanisms whereby polyphenols exert their beneficial health effects. Recent evidence challenges the concept that the health benefits of polyphenols are mainly attributed to their scavenging of free radicals, which may be an oversimplified view. Indeed, cells responding to polyphenol treatment can elicit changes in a number of receptors or enzymes involved in signal transduction (Scalbert, Johnson \& Saltmarsh, 2005). In addition, polyphenols can also potentially bind directly to membrane components such as lipids, proteins and receptors (eg. EGCG was identified as the agonist of laminin receptor (67LR) with high affinity (in nanomolar $\mathrm{K}_{\mathrm{d}}$ value) (Tachibana, Koga, Fujimura, \& Yamada, 2004)). Furthermore, polyphenols may also undergo extensive biotransformation including phase I and phase II metabolism reactions in enterocytes and liver and be fermented by gut microbiota in vivo, to form a range of metabolites (Luca et al., 2019). Studies have also revealed that plant polyphenols may help the body to produce and utilize shortchain fatty acids (SCFAs) in the gut (Parkar, Trower, \& Stevenson, 2013), which is associated with a range of potential health benefits and act as the natural ligands for GPR41/43 (Li et al., 2018; Hu, Lin, Zheng, \& Cheung, 2018). Along with the advancing research on the biological effects of polyphenols and their metabolites, increasing evidence has highlighted the capacity of dietary polyphenols to promote adipose tissue browning and thereafter improve metabolic homeostasis and decrease body weight. In the current review, we critically evaluate the previous studies reporting the possible mechanisms of dietary polyphenols promoting WAT browning.

\section{Dietary polyphenols induce browning of white adipose tissue (WAT)}

Both classical brown adipocytes and beige adipocytes are found to induce lipid mobilization to produce heat, a function mediated by $U C P 1$ which is located on the inner membrane of mitochondria (Lo \& Sun, 2013). Various nutritional agents that promote the conversion of white adipocytes to brown adipocytes also display the ability to induce thermogenesis (Azhar, Parmar, Miller, Samuels, \& Rayalam, 2016; Bonet, Oliver, \& Palou, 2013; P. Lee \& Greenfield, 2015; Merlin et al., 2016). BAT is a highly metabolically active tissue important for heat production and its contribution to thermogenesis in humans could range from 27-123 kcal per day at room temperature and 46-211 kcal per day during mild cold exposure (Carpentier et al., 2018). Interestingly, the reduction in BAT volume and/or activity in human has been associated with both adiposity (van Marken Lichtenbelt et al., 2009) and diabetic status (Ouellet et al., 2011). Furthermore, a recent study demonstrated induced pluripotent stem cells reprogrammed from adipogenic precursors of patients with type 2 diabetes can be induced into beige adipocytes with increased thermogenic function and anti-diabetic secretion (Su et al., 2018). Therefore, increasing the number or activity of brown adipocytes (as well as beige adipocytes) may be a safe and sustainable way to combat obesity and diabetes. A number of studies have observed that food-derived ingredients, such as saponins (eg. soyasaponin Ab), fatty acids (eg. eicosapentaenoic acid) and even plant pigments (eg. fucoxanthin) effectively activate adipose tissue browning (Kim et al., 2019; Fleckenstein-Elsen et al., 2016; Woo et al., 2009). Among these studies, polyphenols were consistently found as phytochemicals inducing browning in WAT. 
For example, resveratrol was found to be capable of stimulating energy expenditure and ameliorating WAT deposition by browning adipose tissue (Zou et al., 2017); in high-fat and highfructose diet fed mice vanillic acid could accelerate thermogenesis and mitochondrial synthesis in both classical BAT and inguinal WAT (X. Han et al., 2018). Similarly, cinnamaldehyde also dose-dependently decreased visceral WAT deposition, partly mediated by activating interscapular BAT, as evidenced by increased UCPI expression (Tamura, Iwasaki, Narukawa, \& Watanabe, 2012). A polyphenol mixture can also relieve obesity and lipid accumulation through induction of beige adipocytes. For example, a recent study showed a water extraction of immature Citrus reticulata rich in synephrine, narirutin, hesperidin, nobiletin, and tangeretin can markedly relieve HFD induced obesity in C57BL/6 Mice by promoting browning of inguinal WAT (Chou, Ho, \& Pan, 2018). Therefore, a positive relationship may exist between dietary polyphenols and WAT browning, and the underlying mechanisms are worthy of exploration.

\subsection{Dietary polyphenols increase sympathetic activity}

Neuronal release of noradrenaline (sympathetic nervous system activation) has been demonstrated to be one of the most important factors regulating WAT browning upon cold stimulation. Evidence has shown that dietary polyphenols may influence this browning by increasing sympathetic nervous system activity. For example, as catechin-polyphenols can function to inhibit catechol-O-methyltransferase (the enzyme that catalyzes noradrenaline degradation) (Shixian, VanCrey, Shi, Kakuda, \& Jiang, 2006), they have the potential to increase sympathetic activity representing an important mechanism for dietary polyphenols inducing WAT browning. In addition, using pre-adipocytes models, trans-cinnamic acid was found to induce browning of white adipocytes by activating the $\beta 3$-AR and $A M P K$ signaling pathways, suggesting its potential to directly activate adrenergic receptors in adipocytes (Kang, Mukherjee, \& Yun, 2019).

\subsection{Dietary polyphenols activate $A M P K-S I R T 1-P G C 1 \alpha$ pathway}

The pathway of $A M P K-S I R T 1-P G C 1 \alpha$ axis is believed to function as a metabolic sensor involved in the regulation of brown or beige adipogenesis (Mele et al., 2017). AMPK phosphorylation is often strongly associated with the browning of adipose tissue accompanied with upregulation of thermogenic markers (Hutchinson, Chernogubova, Dallner, Cannon, \& Bengtsson, 2005; Mulligan, Gonzalez, Stewart, Carey, \& Saupe, 2007; X. Zhang et al., 2016). Consequently, $A M P K$ activators (eg. 5-aminoimidazole-4-carboxamide ribonucleotide) are found to promote the acquisition of BAT-like characteristics in the WAT of mice (Vila-Bedmar, Lorenzo, \& FernándezVeledo, 2010). Furthermore, Mottillo et al. reported that adipocyte-specific deletion of AMPK resulted in a reduction in thermogenesis (Mottillo et al., 2016), suggesting a significant role of $A M P K$ in BAT activation. AMPK activation also promotes the enhancement of sirtuin 1 (SIRT1) activity by upregulating cellular $\mathrm{NAD}^{+}$levels, decreasing NAM levels and phosphorylation of $P G C 1 \alpha$ (Borriello, Cucciolla, Della Ragione, \& Galletti, 2010). In adipocytes it was also found that $S I R T 1$ activation increased AMPK activity and SIRT1 inhibitors decreased AMPK activity. Since $A M P K$ and SIRT1 can regulate each other reciprocally, this hints $A M P K$ and SIRT1 could partner as cellular energy status sensors (AMP/ATP; NAD $/ \mathrm{NAM}$ ) to regulate adipocyte browning. Furthermore, as a histone/protein deacetylase, SIRT1 can also enhance WAT browning by deacetylating PPAR $\gamma$ on Lys 268 and Lys 293 and recruiting PRDM16, a key coactivator for the modulation of mitochondrial function and development of BAT (Qiang et al., 2012). 
Interestingly, a considerable amount of literature has been published that polyphenols play an important role in activating the AMPK-SIRT1-PGCl $\alpha$ pathway (Mele et al., 2017; Silvester, Aseer, \& Yun, 2019). For example, improved glucose homeostasis and insulin sensitivity were obtained with gallic acid administration (at $10 \mathrm{mg} / \mathrm{kg}$ body weight) to C57BL/6 mice fed high-fat diet (HFD) for 9 weeks. The resulting body weight loss and metabolic improvement is likely due to the upregulation of thermogenesis-related genes (UCP1, PGCl $\alpha$, and PPAR $\gamma$ ), which were related to increased $A M P K$ phosphorylation and SIRT1 and $P G C 1 \alpha$ protein levels, suggesting the critical role of the AMPK-SIRT1-PGC1 $\alpha$ pathway in gallic acid's action (Doan et al., 2015). Accumulating evidence also indicates favorable effects of resveratrol on metabolic syndromes including obesity and type 2 diabetes. Wang et al. found that resveratrol induced the browning of inguinal white adipocytes via $A M P K$ activation that led to enhanced expression of a number of beigespecific gene markers (SIRT1, PRDM16, PGC1 $\alpha, P D H$ and UCP1), suggesting its beneficial antiobesity effects may be partly ascribed to WAT browning (S. Wang et al., 2015). The flavonoid and phenolic acid-rich oolong, pu-erh, and particularly black tea have the potential to exert antiobesity properties. This is also partly associated with $A M P K$ activation in WAT and the browning of mesenteric WAT (Yamashita et al., 2014). In agreement with these studies, chrysin was also found to induce 3T3-L1 adipocyte browning through $A M P K$ activation and elevating PGC1 $\alpha$ expression (Choi J, \& Yun J, 2019). Collectively, these findings indicate that natural polyphenols may activate the browning of adipose tissues based on signaling through AMPK-SIRT1-PGC1 $\alpha$ (Figure 3).

\subsection{Dietary polyphenols activate the Protein kinase A (PKA) Signaling Pathway}

Protein kinase $\mathrm{A}(P K A)$ is a downstream target of $\beta 3$-adrenergic receptor ( $\beta 3 \mathrm{AR}$ ) signaling, which is expressed primarily in adipocytes (Klein et al., 1999). As shown in Figure 4, activated PKA is able to phosphorylate cAMP-response element binding protein (CREB) and trigger enhanced expression of thermogenesis and mitochondrial biogenesis related genes (Kim \& Park, 2010; van Dam, Kooijman, Schilperoort, Rensen, \& Boon, 2015; Wood Dos Santos et al., 2018). Moreover, PKA also activates hormone sensitive lipase (HSL), which stimulates lipolysis from stored energy in adipocytes providing free fatty acids for heat production via uncoupled respiration or ATP synthesis (Lowell \& Spiegelman, 2000). There is evidence that some polyphenols may increase cAMP levels to activate the PKA pathway and consequently induce thermogenic gene expression (da-Silva et al., 2007; Tennen, Michishita-Kioi, \& Chua, 2012). Thus, activating the PKA signaling pathway could be another possible mechanism for browning adipose tissues by phenolics. For example, the monoterpene phenolic compound thymol has been demonstrated to exert a browning action via activation of the $\beta$-adrenergic receptor and phosphorylated $P K A$, thereby triggering $U C P 1$ expression in 3T3-L1 adipocytes, suggesting that PKA signaling may be indispensable for thymol exerting its effects (J. H. Choi, Kim, Yu, \& Yun, 2017). Similarly, it has been reported that quercetin increases the levels of UCP1 in both WAT and BAT of HFD-fed mice accompanied by increases in the transcription of thermogenesis-related genes (eg., PRDM16, CIDEA, TFAM, NRF-1, PGCl $\alpha$ ), which is associated with sympathetic stimulation through $\beta 3 \mathrm{AR}$ signaling-induced $P K A$ activation (H. Choi, Kim, \& Yu, 2019). In addition, nobiletin, a polymethoxylated flavone, has been reported to show anti-obesity effects, which were relevant 
promoted the browning of 3T3-L1 adipocytes with increased expression of beige-specific genes including CD137, CIDEA, TBX1, and TMEM26 via the PKA signaling pathway (Jameel Lone, Parray, \& Yun, 2018). Based on the above reports, dietary polyphenols may act as browning and thermogenic activators and their actions can be explained, at least in part, by activation of $P K A$ signaling.

\subsection{Dietary polyphenols activate $M A P K$ Signaling Pathway}

Mitogen-activated protein kinases $(M A P K)$ are a type of serine/threonine protein kinases (Johnson \& Lapadat, 2002). Activation of $M A P K s$, especially $p 38$, were found to drive the browning process of adipocytes (Cao et al., 2004; Robidoux et al., 2005). MAPK is associated with phosphorylation of the transcription factor $C R E B$, which was identified as a key modulator for $U C P 1$ transcription during brown and beige adipogenesis (Martinez-deMena \& Obregon, 2005; Muller et al., 2013). In addition, the MAPK pathway was also found to turn on transcription of PPAR , PGC1 $\alpha$ and UCP1 via phosphorylating the cAMP-dependent transcription factor ATF-2 (Cao et al., 2004). Polyphenols are reported to influence browning of adipocytes by activating the MAPK signaling pathway. Indeed, grape pomace extract, which is rich in a wide variety of phenolics and flavonoids, can stimulate the recruitment of beige adipocytes in vitro and in HFD-fed rats. The underlying mechanisms can be partly attributed to the activation of $p 38$ and ERK1/2 (C. Rodriguez Lanzi et al., 2017; C. Rodriguez Lanzi et al., 2018). Another interesting case reported by Cong et al., showed Pycnogenol, a mixture of procyanidins, phenolic acids, and bioflavonoids promotes browning, which was tightly coordinated with phosphorylation of $P K A$ as well as $p 38$ proteins (Cong et al., 2018) Thus, $M A P K$ activation by polyphenols may represent an important signaling event to coordinate the recruitment of beige adipocytes in WAT.

\subsection{Dietary polyphenols modulate epigenetic processes}

Epigenetic processes including DNA methylation histone modifications and miRNAs are also involved in the control of WAT transdifferentiation. Evidence supports that polyphenol-related epigenetic modifications may also associate with their WAT "browning" activity. For example, apple polyphenols affect $P G C 1 \alpha$ promoter methylation levels and consequently increase its mRNA expression in epididymal adipocytes from high-fat sucrose fed rats (Boqué et al., 2013). Considering the importance of $P G C 1 \alpha$ in WAT browning, it is highly possible that apple polyphenols may affect WAT browning via this epigenetic modulation, although direct evidence may be still inadequate. miRNA networks also represent a fundamental layer in the regulation of gene expression (Bartel, 2004). With understanding of the mechanisms behind the "browning" process increasing, the correlation between miRNAs and beige adipogenesis has been identified (Goody \& Pfeifer, 2019). They either enhance or suppress brown/beige adipogenesis via regulating genes involved in this process (Chen, Pan, \& Pfeifer, 2017). Notably, an adipocyte-specific Dicer ablation led to the "whitening" of murine interscapular BAT (Mori et al., 2012), also demonstrating the requirement of miRNA processing for brown adipogenesis. Evidence indicates that phenolics may regulate the browning via affecting miRNAs. Resveratrol reduces obesity alongside increasing miRNAs (miR-129, miR-328-5p and miR-539-5p), whose predicted target genes are key regulators of browning including PPAR $\gamma$ and HSL (Gracia et al., 2016). In addition, polyphenol-rich green tea extract also showed pro-browning effects by down-regulating miR-335 expression (Otton et al., 2018). These pieces of evidence together indicate the importance of the regulatory effects of miRNAs in 
mediating the actions of dietary phenolics in the browning process of white adipocytes.

\subsection{Dietary polyphenols increase cyclooxygenase-2 activity}

Cyclooxygenase $(C O X)$-2, a rate-limiting enzyme for prostaglandin synthesis, has been shown to regulate whole-body energy homeostasis (Vegiopoulos et al., 2010). In particular, increased COX2 activity is related to the emergence of brown fat features in WAT by inducing brown adipogenic gene expression (Vegiopoulos et al., 2010). Madsen et al. also found that decreased Cox-2 activity caused weight gain along with lowered diet-induced UCP1 expression in inguinal WAT (Madsen et al., 2010). This indicates $C O X-2$ activation seems to be a vital mechanism involved in beige adipogenesis. Interestingly, the combination of resveratrol and quercetin has been found to induce a brown-like remodeling in perirenal WAT with the upregulated expression of UCP1 protein (Arias et al., 2017). The increased mitochondrial activity was co-incident with increased Cox-2 expression. A similar observation was reported in quercetin-treated rats where the expression of Cox-2 was modestly increased (Arias, Macarulla, Aguirre, Martinez-Castano, \& Portillo, 2014). Therefore, manipulation of Cox-2 expression seems to be another possible way for dietary polyphenols to enhance BAT activity and WAT browning, which protects against energy surplus and body weight gain.

\subsection{Dietary polyphenols increase Glucagon-Like Peptide-1}

Glucagon-like peptide 1 (GLP-1) is an incretin hormone released by L-cells (Drucker, 2007; Goke, Fehmann, \& Goke, 1991). GLP-1 binds to the GLP-1 receptor (Campbell \& Drucker, 2013; J. Zhang et al., 2018), and ameliorates obesity via numerous physiological effects. Although its most striking characteristic may be the stimulatory effects on insulin secretion, GLP-1 anti-obesity effects also partly result from increasing thermogenesis and browning (Gu et al., 2011; Lockie et al., 2012; J. Zhang et al., 2018). Evidence also points to inhibition of dipeptidyl peptidase-4 (DPP-4) (the enzyme that efficiently degrades $G L P-1$ in vivo and thus shortens the circulation half-life of GLP-1 to less than 2 min (Deacon et al., 1995)), as a mechanism by which polyphenols increase GLP-1 and leads to elevated expression of PPAR $\alpha, P G C l \alpha$ and $U C P s$ in BAT of obese mice (Shimasaki et al., 2013) and increased metabolic gene expression in human (pre)adipocytes via upregulating PGC1 $\alpha$.

Dietary phenolics such as curcumin and caffeoylquinic acid derivatives are reported to possess GLP1 secretion-stimulating functions (Tsuda, 2015); in addition, polyphenols such as resveratrol, luteolin and apigenin also can exert DPP-4 inhibitory effects, leading to a prolonged action of GLP1 (Habtemariam \& Varghese, 2014; Pinent, Blay, Serrano, \& Ardevol, 2017). Another study also found grape seed extract containing abundant procyanidins resulted in increased levels of active GLP-1 by lowering DPP-4 activity (Gonzalez-Abuin et al., 2014). A study in HFD-fed mice also demonstrated that the flavonoid eriodictyol can exert beneficial effects on alleviating adiposity by significantly increasing the levels of UCP1 in epididymal WAT, which was accompanied by increased circulating GLP-1 (Kwon \& Choi, 2019). However, more studies are needed to elucidate the relationship between dietary phenolics, GLP-1 activity and beige adipogenesis.

\subsection{Dietary polyphenols promote irisin secretion}

The myokine irisin (Bostrom et al., 2012), which is cleaved from the transmembrane protein 
fibronectin type III domain-containing protein 5 (FNDC5), was discovered as the key factor regulating exercise-induced browning of WAT (Mahajan \& Patra, 2013; McMillan \& White, 2015; Y. Zhang et al., 2016). FNDC5/irisin is mainly secreted by skeletal muscle upon exercise and facilitates white adipocyte browning via activating $p 38$ and $E R K$ signal pathways (Y. Zhang et al., 2014). The researchers confirmed that intravenous injection of irisin-expressing adenovirus can induce brown-fat-like development with increased thermogenic gene expression and energy expenditure (Bostrom et al., 2012). Therefore, the intake of irisin-activating ingredients is a mechanism to activate browning of adipose tissues, which would lead to accelerated metabolism and reduced body weight and fat. Some reports claim that polyphenols such as quercetin, apigenin, dihydromyricetin can promote irisin secretion (Jang et al., 2017; Leiherer et al., 2016; Zhou et al., 2015). Genistein was also found to promote browning of subcutaneous WAT in mice through induction of FNDC5 expression in skeletal muscle and increasing irisin levels (Palacios-González et al., 2019). In one study, obese mice treated with leucine-resveratrol combinations for 6 weeks showed two-fold increase in $P G C l \alpha$ and augmented $U C P 1$ expression in WAT accompanied by elevated plasma irisin levels, showing the treatment combination may lead to browning of adipose tissue via promotion of irisin secretion (Baggett, Bruckbauer, \& Zemel, 2013). Similarly, raspberry supplementation, which contains high amounts of polyphenols, also drove the browning of WAT, which was associated with elevated irisin (Xing et al., 2018). Therefore, polyphenols may stimulate browning of WAT due to a positive action on irisin secretion.

\subsection{Capsaicin activates transient receptor potential cation channel subfamily $\mathrm{V}$ member 1 (TRPV1)}

Capsaicin (8-methyl-N-vanillyl-6-nonenamide) is an active constituent of hot pepper, which provides an example of a phenolic compound that promotes browning via binding to membrane receptors (Yang et al., 2015). Capsaicin has elicited interest in anti-obesity research for a long time due to the capability to enhance energy expenditure (Ohnuki et al., 2001). Consumption of capsaicin was found to increase energy expenditure and fat oxidation in human (Janssens et al., 2013). In particular, capsaicin can promote both brown and beige adipogenesis (Kawabata et al., 2009; Ohyama et al., 2016; Ono et al., 2011). Several mechanisms have been proposed. TRPV1 receptors in the intestinal tract can be activated by the consumption of capsaicin or capsaicin-containing food. This causes stimulation of vagal afferent pathways which leads to the activation of neurons within the ventromedial hypothalamus, and thus activates adrenergic pathways to induce brown and beige adipogenesis (Ohyama et al., 2016; Ono et al., 2011). Moreover, Baboota et al. showed that capsaicin also triggered the beige phenotype in 3T3-L1 preadipocytes via its receptor TRPV1 in vitro (Baboota et al., 2014), suggesting the centrally mediated effect of capsaicin was not the only mechanism underlying the browning process.

\subsection{Dietary polyphenols influence gut microbiota composition and short-chain fatty acid production}

The gut microbiota has been recognized as an important modulator of energy balance (Koren et al., 2012; Ridaura et al., 2013). For example, evidence from fecal transplantation experiments suggested that gut microbiota may regulate host energy homeostasis and insulin resistance via a range of possible mechanisms including influencing gut physiology and gut motility, affecting calorie and nutrient harvest, and triggering innate immune responses (Ley et al., 2005; Singh et al., 2017). 
Changes in gut microbiota composition show a strong interaction with expression of browningspecific genes in adipose tissue and energy homeostasis (Chevalier et al., 2015; Fabbiano et al., 2018). A recent study in obese subjects demonstrated a significant positive association between the relative abundance of Firmicutes and the expression of brown marker genes PRDM16, DIO2 and UCP1 in subcutaneous WAT (Moreno-Navarrete et al., 2018). Dietary polyphenols also play a crucial role in augmenting host-microbial interactions, ultimately resulting in beneficial effects including weight reduction (Valdes et al., 2015; Xue et al., 2016). Evidence suggests the combination of quercetin and resveratrol lowers the ratio of Firmicutes to Bacteroidetes and increases Akkermansia in HFD-fed rats and consequently decreasing body weight gain and visceral (epididymal, perirenal) adipose tissue weight (Zhao et al., 2017). Similarly, an investigation from Anhê et al. (Anhe et al., 2018) found that administration of crude extract of Myrciaria dubia containing proanthocyanidins, flavonols, and phenolic acids to HFD fed mice activated BAT and increased the browning of WAT, which may be related to alteration of the gut microbiota. Subsequent analyses provides more direct evidence that resveratrol induced the emergence of beige adipocytes in WAT by remodeling fecal microbiota (Liao et al., 2018); and similar phenomenon are also presented in the study carried out by Wang et al.(P. Wang et al., 2019) that resveratrol-induced microbiota changes are able to stimulate the development of beige adipocytes in WAT and modulate lipid metabolism. Collectively, polyphenols may function as a potential intervention to improve dysbiosis of the gut microbiota in obesity.

SCFAs trigger a variety of physiological responses, which play important roles in energy metabolism and body weight control (Hu, Lin, Zheng, \& Cheung, 2018). Several studies have confirmed that SCFAs, such as butyrate and acetate, can stimulate brown and beige adipogenesis (Z. Gao et al., 2009; Hu et al., 2016; Sahuri-Arisoylu et al., 2016). Notably, polyphenols not only affect SCFA production via regulating gut microbiota, the polyphenols themselves can be broken down in the gut into SCFAs (Bauer, Williams, Smidt, Mosenthin, \& Verstegen, 2006; Oteiza, Fraga, Mills, \& Taft, 2018; Parkar, Trower, \& Stevenson, 2013). Anaerobic bacteria have been reported to produce acetate and butyrate from several flavonoids by cleaving their ring structure of into hydroxyphenylacetic and hydroxyphenylpropionic acids (Blaut, Schoefer, \& Braune, 2003). As reviewed by Reynes et al. (Reynes, Palou, Rodriguez, \& Palou, 2018), prebiotics such as polyphenols can produce specific postbiotic SCFAs that regulate adaptive thermogenesis via influencing BAT recruitment and WAT browning. The important physiological roles that SCFAs play in regulation of transcription factors associated with adipogenesis and mitochondrial biogenesis in BAT may be through G protein-coupled receptor 41/43 (GPR41/43) signaling (Hu et al., 2016; Kimura et al., 2013; Lu et al., 2016), as shown in Figure 5. Moreover, it is important to consider that the relative abundance of individual SCFAs is affected by the gut microbiota profile. Bacteroidetes primarily generate acetate and propionate, whereas Firmicutes mainly produces butyrate (LeBlanc et al., 2017), which can be shaped by the polyphenol substrate. Thus, the production of SFCAs is a possible mechanism for polyphenols to activate browning of adipose tissues.

\section{Conclusions}

Obesity arises from the imbalance between energy intake and consumption. Commercial antiobesity drugs mainly target appetite suppression or inhibit nutrient absorbance. However, a number 
of side effects have been associated with these drugs such as elevated blood pressure and heart rate, insomnia, stomach ache, constipation, and addiction (Kang \& Park, 2012). Therefore, activating thermogenesis within white adipose tissue represents a future strategy for body weight control. Great efforts have been undertaken to search for natural compounds as "browning agents" to improve energy homeostasis. Although there is currently no evidence that supports any specific food ingredients or nutrients that can lead to weight loss, increasingly studies have pointed out that certain food components can influence the activation of beige adipose tissue. Dietary polyphenols in particular may be eligible candidates due to their capacity to enhance energy expenditure by activating brown adipogenesis. Polyphenols widely exist in fruits, vegetables, and plant-derived beverages and are the most abundant dietary antioxidant. It is estimated that healthy individuals can consume polyphenols up to $1 \mathrm{~g}$ /day (Perez-Jimenez et al., 2011). Many studies have demonstrated polyphenols can protect against the metabolic syndrome although research effort is still needed to evaluate the contribution of polyphenols to induction of WAT browning. Indeed, one study on healthy young women has shown that daily ingestion of a catechin-rich beverage increases brown adipose tissue density, supporting the regulatory effects of polyphenols on brown adipogenesis and browning of WAT may also be applied to humans (Nirengi et al., 2016).

Admittedly, the current knowledge may be still far away from elucidating the detailed mechanisms by which dietary phenolics exert their roles in beige adipogenesis. For example, polyphenols may have complex metabolic fates in vivo (van Duynhoven et al., 2011), making it difficult to determine whether metabolites or polyphenols themselves exert functional effects. Another major difficulty of elucidating the "browning" effects of polyphenols on WAT is polyphenols are extensively conjugated in the body, making it more difficult to explore the biological activities of these conjugated metabolites (Scalbert, Johnson \& Saltmarsh, 2005). Moreover, with a deeper understanding towards the browning phenomenon, even evaluation of the browning effects may require considerable caution when drawing conclusions. For instance, certain high molecular weight polyphenols cannot be directly absorbed by the stomach and small intestine and they are metabolized in the colon (van Duynhoven et al., 2011). Therefore, the cell-autonomous browning effects observed in cellular models may not reflect the overall metabolic effects in vivo, especially when taking into consideration that browning is mainly a sympathetic event. Moreover, the search for browning agents has mostly been investigated in rodent models and there remains a paucity of human studies. Differences between humans and rodents cannot be overlooked. The activity of at least some "browning agents" may simply be a consequence of their epilating effects or curling the fur to cause cold stress in mice (Nedergaard \& Cannon, 2014). Therefore, additional experiments may be needed to evaluate their browning effects in human. Another issue that cannot be ignored is phenolics usually possess a broad range of biological activities relevant to metabolic regulation (Pereira, Valentão, Pereira, \& Andrade, 2009). Therefore, experiments are also required to assess whether the browning is the key cause of the observed metabolic changes. In order to fully understand the contribution of browning to the metabolic changes, the UCP1 knock-out model may be a useful tool to dissect the links between the observation of beige adipocytes in white adipose tissue and the overall metabolic effects of the tested polyphenols (Nedergaard, Matthias, Golozoubova, Jacobsson, \& Cannon, 1999).

In conclusion, current evidence strongly supports that dietary phenolics may play roles in the 
431 browning of white adipose tissue, however, further exploration is needed to define the underlying

432 mechanisms of polyphenols in the framework of WAT browning and BAT activation. More studies

433 are also required to elucidate how much of a role polyphenol-activated browning may play in

434 counteracting human obesity and correlate the biological effects of the polyphenol compounds with

435 their principal metabolites.

436

437

\section{Conflicts of Interest}

438 The authors declare no conflicts of interest.

439

440

\section{Acknowledgments}

441

This work was supported by the Global Challenge Research Fund Visiting Fellowships, National

442 Natural Science Foundation of China [81703065], and China Postdoctoral Science Foundation

443 [2019T120551] for financial support.

444 


\section{Figure Legends}

Fig. 1 Key regulators during the transdifferentiation of white adipocytes into beige adipocytes; and the main differences in the morphology and functions between these two types of adipocytes. WAT is classically spherical, it is full of single lipid droplet, and it contains few mitochondria. BAT is smaller than white. It contains a large number of mitochondria and contains multiple small lipid droplets. Blue: nucleus, green: mitochondria, and yellow: lipid droplets; $C / E B P \beta$ : CCAAT-enhancer-binding protein $\beta ; C t B P 1$ : C-terminal-binding protein 1; PGC1 $\alpha$ : Peroxisome proliferator-activated receptor gamma coactivator-1 $\alpha ;$ PPAR $\gamma$ : Peroxisome proliferator-activated receptor $\gamma$; PRDM16: PR domain-containing 16.

Fig. 2 Classification of polyphenols and the representative structures.

Fig. 3 The possible mechanisms for curcumin inducing "browning" via the AMPK-SIRT1PGC1a pathway (J. Lone, Choi, Kim, \& Yun, 2016; Price et al., 2012; Yuan et al., 2017). ( $\rightarrow$ ) stimulatory, $(\perp)$ inhibitory action, $(\uparrow)$ up-regulation. AMPK: AMP-activated protein kinase; $C / E B P \beta$ : CCAAT-enhancer-binding protein $\beta$; CIDEA: Cell death-inducing DNA fragmentation factor, alpha subunit-like effector A; $C P T 1$ : Carnitine palmitoyl transferase I; HSL: hormone sensitive lipase; $F G F 21$ : fibroblast growth factor $21 ; L K B 1$ : Liver kinase $\mathrm{B} 1 ; \mathrm{NAD}^{+}$: Nicotinamide adenine dinucleotide (oxidized form); $N R F 1$ : Nuclear respiratory factor 1; NRF2: Nuclear respiratory factor 2; $P G C 1 \alpha$ : Peroxisome proliferator-activated receptor gamma coactivator-1 $\alpha$; PPAR $\gamma$ : Peroxisome proliferator-activated receptor $\gamma$; PRDM16: PR domain-containing 16; SIRT1: Sirtuin 1; TBX1: T-box protein 1; TFAM: Mitochondrial transcription factor A; TMEM26: Transmembrane protein 26; UCP1: Uncoupling protein 1;

Fig. 4 Schematic representation of $\boldsymbol{P K A}$ pathways stimulated by polyphenols to activate mitochondrial biogenesis. PKA: Protein kinase A; $C R E B$ : cAMP-response element binding protein; $N R F 1$ : Nuclear respiratory factor $1 ; N R F 2$ : Nuclear respiratory factor $2 ; P G C 1 \alpha$ : Peroxisome proliferator-activated receptor gamma coactivator-1 $\alpha$; TFAM: Mitochondrial transcription factor A; mtDNA: Mitochondrial DNA.

Fig. 5 Polyphenol metabolites SCFAs (eg. acetate and butyrate) stimulate brown adipogenesis and mitochondrial biogenesis via GPR43 and controls mitochondrial biogenesis, resulting in increased BAT activity and adiposity reduction. GPR43: G Protein-coupled Receptor 43; $P G C 1 \alpha$ : peroxisome proliferator-activated receptor gamma coactivator-1 $\alpha$; NRF: Nuclear respiratory factor; TFAM: Mitochondrial transcription factor A. 


\section{References}

Aguirre, L., Milton-Laskibar, I., Hijona, E., Bujanda, L., Rimando, A. M., \& Portillo, M. P. (2016). Effects of pterostilbene in brown adipose tissue from obese rats. Journal of Physiology and Biochemistry, 73(3), 457-464. doi:10.1007/s13105-017-0556-2

Andrade, J. M., Frade, A. C., Guimaraes, J. B., Freitas, K. M., Lopes, M. T., Guimaraes, A. L., . . . Santos, S. H. (2014). Resveratrol increases brown adipose tissue thermogenesis markers by increasing SIRT1 and energy expenditure and decreasing fat accumulation in adipose tissue of mice fed a standard diet. European Journal of Nutrition, 53(7), 1503-1510. doi:10.1007/s00394-014-0655-6

Anhe, F. F., Nachbar, R. T., Varin, T. V., Trottier, J., Dudonne, S., Le Barz, M., . . Marette, A. (2018). Treatment with camu camu (Myrciaria dubia) prevents obesity by altering the gut microbiota and increasing energy expenditure in diet-induced obese mice. Gut, 68(3), 453-464. doi:10.1136/gutjnl-2017-315565

Arias, N., Macarulla, M. T., Aguirre, L., Martinez-Castano, M. G., \& Portillo, M. P. (2014). Quercetin can reduce insulin resistance without decreasing adipose tissue and skeletal muscle fat accumulation. Genes \& Nutrition, 9(1), 361. doi:10.1007/s12263-013-0361-7

Arias, N., Pico, C., Teresa Macarulla, M., Oliver, P., Miranda, J., Palou, A., \& Portillo, M. P. (2017). A combination of resveratrol and quercetin induces browning in white adipose tissue of rats fed an obesogenic diet. Obesity (Silver Spring), 25(1), 111-121. doi:10.1002/oby.21706

Azhar, Y., Parmar, A., Miller, C. N., Samuels, J. S., \& Rayalam, S. (2016). Phytochemicals as novel agents for the induction of browning in white adipose tissue. Nutrition \& Metabolism, 13, 89. doi:10.1186/s12986-016-0150-6

Baboota, R. K., Singh, D. P., Sarma, S. M., Kaur, J., Sandhir, R., Boparai, R. K., . . Bishnoi, M. (2014). Capsaicin induces "brite" phenotype in differentiating 3T3-L1 preadipocytes. PloS One, 9(7), e103093. doi:10.1371/journal.pone.0103093

Baggett, B., Bruckbauer, A., \& Zemel, M. (2013). Synergistic Effects of Leucine and its Metabolites with Polyphenols on Irisin in Myotubes and Diet-induced Obese Mice. The FASEB Journal, 27(1 supplement), 637.611-637.611. doi:10.1096/fasebj.27.1 supplement.637.11

Bartel, D. P. (2004). MicroRNAs: Genomics, Biogenesis, Mechanism, and Function. Cell, 116(2), $281-$ 297. doi:https://doi.org/10.1016/S0092-8674(04)00045-5

Bauer, E., Williams, B. A., Smidt, H., Mosenthin, R., \& Verstegen, M. W. (2006). Influence of dietary components on development of the microbiota in single-stomached species. Nutrition Research Reviews, 19(1), 63-78. doi:10.1079/nrr2006123

Blaut, M., Schoefer, L., \& Braune, A. (2003). Transformation of flavonoids by intestinal microorganisms. International Journal for Vitamin and Nutrition Research, 73(2), 79-87. doi:10.1024/0300-9831.73.2.79

Bonet, M. L., Oliver, P., \& Palou, A. (2013). Pharmacological and nutritional agents promoting browning of white adipose tissue. Biochimica et Biophysica Acta, 1831(5), 969-985. doi:10.1016/j.bbalip.2012.12.002

Boqué, N., de la Iglesia, R., de la Garza, A. L., Milagro, F. I., Olivares, M., Bañuelos, Ó., ... \& Campió n, J. (2013). Prevention of diet-induced obesity by apple polyphenols in W istar rats through regulation of adipocyte gene expression and DNA methylation patterns. Molecular nutrition \& food research, 57(8), 1473-1478.

Borriello, A., Cucciolla, V., Della Ragione, F., \& Galletti, P. (2010). Dietary polyphenols: Focus on 
resveratrol, a promising agent in the prevention of cardiovascular diseases and control of glucose homeostasis. Nutrition, Metabolism and Cardiovascular Diseases, 20(8), 618-625. doi:https://doi.org/10.1016/j.numecd.2010.07.004

Bostrom, P., Wu, J., Jedrychowski, M. P., Korde, A., Ye, L., Lo, J. C., . . Spiegelman, B. M. (2012). A PGC1-alpha-dependent myokine that drives brown-fat-like development of white fat and thermogenesis. Nature, 481(7382), 463-468. doi:10.1038/nature10777

Campbell, J. E., \& Drucker, D. J. (2013). Pharmacology, physiology, and mechanisms of incretin hormone action. Cell Metabolism, 17(6), 819-837. doi:10.1016/j.cmet.2013.04.008

Cao, W., Daniel, K. W., Robidoux, J., Puigserver, P., Medvedev, A. V., Bai, X., . . Collins, S. (2004). p38 mitogen-activated protein kinase is the central regulator of cyclic AMP-dependent transcription of the brown fat uncoupling protein 1 gene. Molecular and Cellular Biology, 24(7), 3057-3067. doi:10.1128/mcb.24.7.3057-3067.2004

Carpentier, A. C., Blondin, D. P., Virtanen K. A., Richard, D., Haman, F., Turcotte, E. E. (2018). Brown Adipose Tissue Energy Metabolism in Humans. Frontiers in Endocrinology, 9, 447. doi: 10.3389/fendo.2018.00447

Cedikova, M., Kripnerova, M., Dvorakova, J., Pitule, P., Grundmanova, M., Babuska, V., .. . Kuncova, J. (2016). Mitochondria in White, Brown, and Beige Adipocytes. Stem Cells International, 2016, 6067349. doi:10.1155/2016/6067349

Chen, Y., Pan, R., \& Pfeifer, A. (2017). Regulation of brown and beige fat by microRNAs. Pharmacology \& Therapeutics, 170, 1-7. doi:10.1016/j.pharmthera.2016.10.004

Chevalier, C., Stojanovic, O., Colin, D. J., Suarez-Zamorano, N., Tarallo, V., Veyrat-Durebex, C., . . . Trajkovski, M. (2015). Gut Microbiota Orchestrates Energy Homeostasis during Cold. Cell, 163(6), 1360-1374. doi:10.1016/j.cell.2015.11.004

Choi, H., Kim, C. S., \& Yu, R. (2019). Quercetin Upregulates Uncoupling Protein 1 in White/Brown Adipose Tissues through Sympathetic Stimulation. Journal of Obesity \& Metabolic Syndrome, 28(1), 71-72. doi:10.7570/jomes.2019.28.1.71

Choi, J. H., Kim, S. W., Yu, R., \& Yun, J. W. (2017). Monoterpene phenolic compound thymol promotes browning of 3T3-L1 adipocytes. European Journal of Nutrition, 56(7), 2329-2341. doi:10.1007/s00394-016-1273-2

Chou, Y. C., Ho, C. T., \& Pan, M. H. (2018). Immature Citrus reticulata Extract Promotes Browning of Beige Adipocytes in High-Fat Diet-Induced C57BL/6 Mice. Journal of Agricultural and Food Chemistry, 66(37), 9697-9703. doi:10.1021/acs.jafc.8b02719

Choi J., \& Yun J. (2019). Chrysin induces brown fat-like phenotype and enhances lipid metabolism in 3T3-L1 adipocytes. Nutrition, 32, 1002-1010. doi: 10.1016/j.nut.2016.02.007

Cong, H., Zhong, W., Wang, Y., Ikuyama, S., Fan, B., \& Gu, J. (2018). Pycnogenol(R) Induces Browning of White Adipose Tissue through the PKA Signaling Pathway in Apolipoprotein EDeficient Mice. Journal of Diabetes Research, 2018, 9713259. doi:10.1155/2018/9713259

Cohen, P., Levy, J. D., Zhang, Y., Frontini, A., Kolodin, D. P., Svensson, K. J., ... \& Wu, J. (2014). Ablation of PRDM16 and beige adipose causes metabolic dysfunction and a subcutaneous to visceral fat switch. Cell, 156(1-2), 304-316. doi:10.1016/j.cell.2013.12.021

da-Silva, W. S., Harney, J. W., Kim, B. W., Li, J., Bianco, S. D., Crescenzi, A., . . Bianco, A. C. (2007). The small polyphenolic molecule kaempferol increases cellular energy expenditure and thyroid hormone activation. Diabetes, 56(3), 767-776. doi:10.2337/db06-1488

Deacon, C. F., Nauck, M. A., Toft-Nielsen, M., Pridal, L., Willms, B., \& Holst, J. J. (1995). Both 
subcutaneously and intravenously administered glucagon-like peptide I are rapidly degraded from the NH2-terminus in type II diabetic patients and in healthy subjects. Diabetes, 44(9), 1126-1131. doi:10.2337/diab.44.9.1126

Doan, K. V., Ko, C. M., Kinyua, A. W., Yang, D. J., Choi, Y. H., Oh, I. Y., . . Kim, K. W. (2015). Gallic acid regulates body weight and glucose homeostasis through AMPK activation. Endocrinology, 156(1), 157-168. doi:10.1210/en.2014-1354

Drucker, D. J. (2007). The role of gut hormones in glucose homeostasis. Journal of Clinical Investigation, 117(1), 24-32. doi:10.1172/jci30076

Engin A. (2017). The Definition and Prevalence of Obesity and Metabolic Syndrome. Advances in Experimental Medicine and Biology, 960,1-17. doi: 10.1007/978-3-319-48382-5_1.

Fabbiano, S., Suarez-Zamorano, N., Chevalier, C., Lazarevic, V., Kieser, S., Rigo, D., . . Trajkovski, M. (2018). Functional Gut Microbiota Remodeling Contributes to the Caloric RestrictionInduced Metabolic Improvements. Cell Metabolism, 28(6), 907-921.e907. doi:10.1016/j.cmet.2018.08.005

Fleckenstein-Elsen, M., Dinnies, D., Jelenik, T., Roden, M., Romacho, T., \& Eckel, J. (2016). Eicosapentaenoic acid and arachidonic acid differentially regulate adipogenesis, acquisition of a brite phenotype and mitochondrial function in primary human adipocytes. Molecular nutrition \& food research, 60(9), 2065-2075.

Gao, J., Ghibaudi, L., van Heek, M., \& Hwa, J. J. (2002). Characterization of diet-induced obese rats that develop persistent obesity after 6 months of high-fat followed by 1 month of low-fat diet. Brain Research, 936(1-2), 87-90. doi:10.1016/s0006-8993(02)02493-9

Gao, Z., Yin, J., Zhang, J., Ward, R. E., Martin, R. J., Lefevre, M., . . Ye, J. (2009). Butyrate improves insulin sensitivity and increases energy expenditure in mice. Diabetes, 58(7), 1509-1517. doi:10.2337/db08-1637

Goke, R., Fehmann, H. C., \& Goke, B. (1991). Glucagon-like peptide-1(7-36) amide is a new incretin/enterogastrone candidate. European Journal of Clinical Investigation, 21(2), 135-144.

Gonzalez-Abuin, N., Martinez-Micaelo, N., Margalef, M., Blay, M., Arola-Arnal, A., Muguerza, B., . . . Pinent, M. (2014). A grape seed extract increases active glucagon-like peptide-1 levels after an oral glucose load in rats. Food \& Function, 5(9), 2357-2364. doi:10.1039/c4fo00447g

Goody, D., \& Pfeifer, A. (2019). MicroRNAs in brown and beige fat. Biochimica et Biophysica Acta Molecular and Cell Biology of Lipids, 1864(1), 29-36. doi:10.1016/j.bbalip.2018.05.003

Gracia, A., Miranda, J., Fernandez-Quintela, A., Eseberri, I., Garcia-Lacarte, M., Milagro, F. I., . . . Portillo, M. P. (2016). Involvement of miR-539-5p in the inhibition of de novo lipogenesis induced by resveratrol in white adipose tissue. Food \& Function, 7(3), 1680-1688. doi:10.1039/c5fo01090j

Gu, W., Lloyd, D. J., Chinookswong, N., Komorowski, R., Sivits, G., Jr., Graham, M., . . Veniant, M. M. (2011). Pharmacological targeting of glucagon and glucagon-like peptide 1 receptors has different effects on energy state and glucose homeostasis in diet-induced obese mice. Journal of Pharmacology and Experimental Therapeutics, 338(1), 70-81. doi:10.1124/jpet.111.179986

Habtemariam, S., \& Varghese, G. K. (2014). The antidiabetic therapeutic potential of dietary polyphenols. Current Pharmaceutical Biotechnology, 15(4), 391-400.

Hall, K. D., Sacks, G., Chandramohan, D., Chow, C. C., Wang, Y. C., Gortmaker, S. L., \& Swinburn, B. A. (2011). Quantification of the effect of energy imbalance on bodyweight. Lancet, 378(9793), 826-837. doi:10.1016/s0140-6736(11)60812-x 
Han, X., Guo, J., You, Y., Yin, M., Liang, J., Ren, C., . . Huang, W. (2018). Vanillic acid activates thermogenesis in brown and white adipose tissue. Food \& Function, 9(8), 4366-4375. doi:10.1039/c8fo00978c

Han, X. Z., Shen, T., \& Lou, H. X. (2007). Dietary polyphenols and their biological significance. International Journal of Molecular Sciences, 8(9), 950-988. doi:DOI 10.3390/i8090950

Harms, M., \& Seale, P. (2013). Brown and beige fat: development, function and therapeutic potential. Nature Medicine, 19(10), 1252-1263. doi:10.1038/nm.3361

$\mathrm{Hu}, \mathrm{J} .$, \& Christian, M. (2017). Hormonal factors in the control of the browning of white adipose tissue. Hormone Molecular Biology and Clinical Investigation, 31(1). doi:10.1515/hmbci-2017-0017

Hu, J., Kyrou, I., Tan, B. K., Dimitriadis, G. K., Ramanjaneya, M., Tripathi, G., . . Randeva, H. S. (2016). Short-Chain Fatty Acid Acetate Stimulates Adipogenesis and Mitochondrial Biogenesis via GPR43 in Brown Adipocytes. Endocrinology, 157(5), 1881-1894. doi:10.1210/en.2015-1944

Hu, J., Lin, S., Zheng, B., \& Cheung, P. C. K. (2018). Short-chain fatty acids in control of energy metabolism. Critical Reviews in Food Science and Nutrition, 58(8), 1243-1249. doi:10.1080/10408398.2016.1245650

Hutchinson, D. S., Chernogubova, E., Dallner, O. S., Cannon, B., \& Bengtsson, T. (2005). Betaadrenoceptors, but not alpha-adrenoceptors, stimulate AMP-activated protein kinase in brown adipocytes independently of uncoupling protein-1. Diabetologia, 48(11), 2386-2395. doi:10.1007/s00125-005-1936-7

Jang, Y. J., Son, H. J., Choi, Y. M., Ahn, J., Jung, C. H., \& Ha, T. Y. (2017). Apigenin enhances skeletal muscle hypertrophy and myoblast differentiation by regulating Prmt7. Oncotarget, 8(45), 78300-78311. doi:10.18632/oncotarget.20962

Janssens, P. L., Hursel, R., Martens, E. A., \& Westerterp-Plantenga, M. S. (2013). Acute effects of capsaicin on energy expenditure and fat oxidation in negative energy balance. PloS One, 8(7), e67786.

Johnson, G. L., \& Lapadat, R. (2002). Mitogen-activated protein kinase pathways mediated by ERK, JNK, and p38 protein kinases. Science, 298(5600), 1911-1912. doi:10.1126/science. 1072682

Kajimura, S., Seale, P., Kubota, K., Lunsford, E., Frangioni, J.V., Gygi, S.P., \& Spiegelman, B.M. (2009). Initiation of myoblast to brown fat switch by a PRDM16-C/EBP-beta transcriptional complex. Nature, 460, 1154-1158.

Kajimura, S., Seale, P., Tomaru, T., Erdjument-Bromage, H., Cooper, M.P., Ruas, J.L., Chin, S., Tempst, P., Lazar, M.A., \& Spiegelman, B.M. (2008). Regulation of the brown and white fat gene programs through a PRDM16/CtBP transcriptional complex. Genes \& Devlopment, 22, 1397-1409.

Kang, J. G., \& Park, C. Y. (2012). Anti-Obesity Drugs: A Review about Their Effects and Safety. Diabetes \& Metabolism Journal, 36(1), 13-25. doi:10.4093/dmj.2012.36.1.13

Kang N., Mukherjee S., \& Yun J. (2019). Trans-Cinnamic Acid Stimulates White Fat Browning and Activates Brown Adipocytes. Nutrients, 11(3), 577. doi: 10.3390/nu11030577

Kawabata, F., Inoue, N., Masamoto, Y., Matsumura, S., Kimura, W., Kadowaki, M., . . Fushiki, T. (2009). Non-pungent capsaicin analogs (capsinoids) increase metabolic rate and enhance thermogenesis via gastrointestinal TRPV1 in mice. Bioscience Biotechnology and Biochemistry, 73(12), 2690-2697. doi:10.1271/bbb.90555

Kim, A., \& Park, T. (2010). Diet-induced obesity regulates the galanin-mediated signaling cascade in 
the adipose tissue of mice. Molecular Nutrition \& Food Research, 54(9), 1361-1370. doi:10.1002/mnfr.200900317

Kim, H. J., Choi, E. J., Kim, H. S., Choi, C. W., Choi, S. W., Kim, S. L., ... \& Do, S. H. (2019). Soyasaponin $\mathrm{Ab}$ alleviates postmenopausal obesity through browning of white adipose tissue. Journal of Functional Foods, 57, 453-464.

Kimura, I., Ozawa, K., Inoue, D., Imamura, T., Kimura, K., Maeda, T., ... Tsujimoto, G. (2013). The gut microbiota suppresses insulin-mediated fat accumulation via the short-chain fatty acid receptor GPR43. Nature Communications, 4, 1829. doi:10.1038/ncomms 2852

Kiskinis, E., Chatzeli, L., Curry, E., Kaforou, M., Frontini, A., Cinti, S., . . Christian, M. (2014). RIP140 represses the "brown-in-white" adipocyte program including a futile cycle of triacylglycerol breakdown and synthesis. Molecular Endocrinology, 28(3), 344-356. doi:10.1210/me.2013-1254

Kissig, M., Shapira, S. N., \& Seale, P. (2016). SnapShot: Brown and Beige Adipose Thermogenesis. Cell, 166(1), 258-258.e251. doi:10.1016/j.cell.2016.06.038

Klein, J., Fasshauer, M., Ito, M., Lowell, B. B., Benito, M., \& Kahn, C. R. (1999). beta(3)-adrenergic stimulation differentially inhibits insulin signaling and decreases insulin-induced glucose uptake in brown adipocytes. Journal of Biological Chemistry, 274(49), 34795-34802. doi:10.1074/jbc.274.49.34795

Kleiner, S. , Mepani, R. J. , Laznik, D. , Ye, L., Jurczak, M. J. , Jornayvaz, F. R., . . Spiegelman B. M. (2012). Development of insulin resistance in mice lacking PGC1alpha in adipose tissues. Proceedings of the National Academy of Sciences, 109(24), 9635-9640.

Koren, O., Goodrich, J. K., Cullender, T. C., Spor, A., Laitinen, K., Backhed, H. K., . . . Ley, R. E. (2012). Host remodeling of the gut microbiome and metabolic changes during pregnancy. Cell, 150(3), 470-480. doi:10.1016/j.cell.2012.07.008

Kwon, E. Y., \& Choi, M. S. (2019). Dietary Eriodictyol Alleviates Adiposity, Hepatic Steatosis, Insulin Resistance, and Inflammation in Diet-Induced Obese Mice. International Journal of Molecular Sciences, 20(5). doi:10.3390/ijms20051227

Lagouge, M., Argmann, C., Gerhart-Hines, Z., Meziane, H., Lerin, C., Daussin, F., . . Auwerx, J. (2006). Resveratrol improves mitochondrial function and protects against metabolic disease by activating SIRT1 and PGC1alpha. Cell, 127(6), 1109-1122. doi:10.1016/j.cell.2006.11.013

LeBlanc, J. G., Chain, F., Martin, R., Bermudez-Humaran, L. G., Courau, S., \& Langella, P. (2017). Beneficial effects on host energy metabolism of short-chain fatty acids and vitamins produced by commensal and probiotic bacteria. Microbial Cell Factories, 16(1), 79. doi:10.1186/s12934-017-0691-z

Lee, M. S., Shin, Y., Jung, S., \& Kim, Y. (2017). Effects of epigallocatechin-3-gallate on thermogenesis and mitochondrial biogenesis in brown adipose tissues of diet-induced obese mice. Food \& Nutrition Research, 61(1), 1325307. doi:10.1080/16546628.2017.1325307

Lee, P., \& Greenfield, J. R. (2015). Non-pharmacological and pharmacological strategies of brown adipose tissue recruitment in humans. Molecular and Cellular Endocrinology, 418 Pt 2, 184190. doi:10.1016/j.mce.2015.05.025

Lee, Y. H., Jung, Y. S., \& Choi, D. (2014). Recent advance in brown adipose physiology and its therapeutic potential. Experimental and Molecular Medicine, 46, e78. doi:10.1038/emm.2013.163

Leiherer, A., Stoemmer, K., Muendlein, A., Saely, C. H., Kinz, E., Brandtner, E. M., . . . Drexel, H. 
(2016). Quercetin Impacts Expression of Metabolism- and Obesity-Associated Genes in SGBS Adipocytes. Nutrients, 8(5). doi:10.3390/nu8050282

Ley, R. E., Backhed, F., Turnbaugh, P., Lozupone, C. A., Knight, R. D., \& Gordon, J. I. (2005). Obesity alters gut microbial ecology. Proceedings of the National Academy of Sciences of the United States of America, 102(31), 11070-11075. doi:10.1073/pnas.0504978102

Li, Z., Yi, C. X., Katiraei, S., Kooijman, S., Zhou, E., Chung, C. K., . . Wang, Y. (2018). Butyrate reduces appetite and activates brown adipose tissue via the gut-brain neural circuit. Gut, 67(7), 1269-1279. doi:10.1136/gutjnl-2017-314050

Liao, W., Yin, X., Li, Q., Zhang, H., Liu, Z., Zheng, X., . . Feng, X. (2018). Resveratrol-Induced White Adipose Tissue Browning in Obese Mice by Remodeling Fecal Microbiota. Molecules, 23(12). doi:10.3390/molecules23123356

Lidell, M. E., Betz, M. J., Leinhard, O. D., Heglind, M., Elander, L., Slawik, M., . . Enerbäck, S. (2013). Evidence for two types of brown adipose tissue in humans. Nature Medicine, 19, 631. doi: $10.1038 / \mathrm{nm} .3017$

Lo, K. A., \& Sun, L. (2013). Turning WAT into BAT: a review on regulators controlling the browning of white adipocytes. Bioscience Reports, 33(5). doi:10.1042/bsr20130046

Lockie, S. H., Heppner, K. M., Chaudhary, N., Chabenne, J. R., Morgan, D. A., Veyrat-Durebex, C., .. . Perez-Tilve, D. (2012). Direct control of brown adipose tissue thermogenesis by central nervous system glucagon-like peptide-1 receptor signaling. Diabetes, 61(11), 2753-2762. doi:10.2337/db11-1556

Lone, J., Choi, J. H., Kim, S. W., \& Yun, J. W. (2016). Curcumin induces brown fat-like phenotype in 3T3-L1 and primary white adipocytes. Journal of Nutritional Biochemistry, 27, 193-202. doi:10.1016/j.jnutbio.2015.09.006

Lone, J., Parray, H. A., \& Yun, J. W. (2018). Nobiletin induces brown adipocyte-like phenotype and ameliorates stress in 3T3-L1 adipocytes. Biochimie, 146, 97-104. doi:https://doi.org/10.1016/j.biochi.2017.11.021

Lowell, B. B., \& Spiegelman, B. M. (2000). Towards a molecular understanding of adaptive thermogenesis. Nature, 404, 652. doi:10.1038/35007527

Lu, Y., Fan, C., Li, P., Lu, Y., Chang, X., \& Qi, K. (2016). Short Chain Fatty Acids Prevent High-fatdiet-induced Obesity in Mice by Regulating G Protein-coupled Receptors and Gut Microbiota. Scientific Reports, 6, 37589. doi:10.1038/srep37589

Luca S.V., Macovei I., Bujor A., Miron A., Skalicka-Woźniak K., Aprotosoaie A.C., Trifan A. (2019). Bioactivity of dietary polyphenols: The role of metabolites. Critical Reviews in Food Science and Nutrition, 2019 Jan 7:1-34. doi: 10.1080/10408398.2018.1546669.

Madsen, L., Pedersen, L. M., Lillefosse, H. H., Fjaere, E., Bronstad, I., Hao, Q., . . Kristiansen, K. (2010). UCP1 induction during recruitment of brown adipocytes in white adipose tissue is dependent on cyclooxygenase activity. PloS One, 5(6), e11391. doi:10.1371/journal.pone.0011391

Mahajan, R. D., \& Patra, S. K. (2013). Irisin, a novel myokine responsible for exercise induced browning of white adipose tissue. Indian Journal of Clinical Biochemistry, 28(1), 102-103. doi:10.1007/s12291-012-0255-2

Martinez-deMena, R., \& Obregon, M. J. (2005). Insulin increases the adrenergic stimulation of 5' deiodinase activity and mRNA expression in rat brown adipocytes; role of MAPK and PI3K. Journal of Molecular Endocrinology, 34(1), 139-151. doi:10.1677/jme.1.01568 
McMillan, A. C., \& White, M. D. (2015). Induction of thermogenesis in brown and beige adipose tissues: molecular markers, mild cold exposure and novel therapies. Current Opinion in Endocrinology Diabetes and Obesity, 22(5), 347-352. doi:10.1097/med.0000000000000191

Mele, L., Bidault, G., Mena, P., Crozier, A., Brighenti, F., Vidal-Puig, A., \& Del Rio, D. (2017). Dietary (Poly)phenols, Brown Adipose Tissue Activation, and Energy Expenditure: A Narrative Review. Advances in Nutrition, 8(5), 694-704. doi:10.3945/an.117.015792

Merlin, J., Evans, B. A., Dehvari, N., Sato, M., Bengtsson, T., \& Hutchinson, D. S. (2016). Could burning fat start with a brite spark? Pharmacological and nutritional ways to promote thermogenesis. Molecular Nutrition \& Food Research, 60(1), 18-42. doi:10.1002/mnfr.201500251

Moreno-Navarrete, J. M., Serino, M., Blasco-Baque, V., Azalbert, V., Barton, R. H., Cardellini, M., . . Fernandez-Real, J. M. (2018). Gut Microbiota Interacts with Markers of Adipose Tissue Browning, Insulin Action and Plasma Acetate in Morbid Obesity. Molecular Nutrition \& Food Research, 62(3). doi:10.1002/mnfr.201700721

Mori, M. A., Raghavan, P., Thomou, T., Boucher, J., Robida-Stubbs, S., Macotela, Y., . . Kahn, C. R. (2012). Role of microRNA processing in adipose tissue in stress defense and longevity. Cell Metabolism, 16(3), 336-347. doi:10.1016/j.cmet.2012.07.017

Mottillo, E. P., Desjardins, E. M., Crane, J. D., Smith, B. K., Green, A. E., Ducommun, S., . . . Steinberg, G. R. (2016). Lack of Adipocyte AMPK Exacerbates Insulin Resistance and Hepatic Steatosis through Brown and Beige Adipose Tissue Function. Cell Metabolism, 24(1), 118-129. doi:10.1016/j.cmet.2016.06.006

Muller, T. D., Lee, S. J., Jastroch, M., Kabra, D., Stemmer, K., Aichler, M., . . Tschop, M. H. (2013). p62 links beta-adrenergic input to mitochondrial function and thermogenesis. Journal of Clinical Investigation, 123(1), 469-478. doi:10.1172/jci64209

Mulligan, J. D., Gonzalez, A. A., Stewart, A. M., Carey, H. V., \& Saupe, K. W. (2007). Upregulation of AMPK during cold exposure occurs via distinct mechanisms in brown and white adipose tissue of the mouse. Journal of Physiology, 580(Pt. 2), 677-684. doi:10.1113/jphysiol.2007.128652

Nedergaard, J., \& Cannon, B. (2014). The browning of white adipose tissue: some burning issues. Cell Metabolism, 20(3), 396-407. doi:10.1016/j.cmet.2014.07.005

Nedergaard, J., Matthias, A., Golozoubova, V., Jacobsson, A., \& Cannon, B. (1999). UCP1: the original uncoupling protein--and perhaps the only one? New perspectives on UCP1, UCP2, and UCP3 in the light of the bioenergetics of the UCP1-ablated mice. Journal of Bioenergetics and Biomembranes, 31(5), 475-491.

Nirengi, S., Amagasa, S., Homma, T., Yoneshiro, T., Matsumiya, S., Kurosawa, Y., ... \& Hamaoka, T. (2016). Daily ingestion of catechin-rich beverage increases brown adipose tissue density and decreases extramyocellular lipids in healthy young women. Springerplus, 5(1), 1363.

Ohno H, Shinoda K, Spiegelman BM, Kajimura S. (2012). PPAR $\gamma$ agonists induce a white-to-brown fat conversion through stabilization of PRDM16 protein. Cell Metabolism, 15(3), 395-404. doi:10.1016/j.cmet.2012.01.019.

Ohnuki, K., Haramizu, S., Oki, K., Watanabe, T., Yazawa, S., \& Fushiki, T. (2001). Administration of capsiate, a non-pungent capsaicin analog, promotes energy metabolism and suppresses body fat accumulation in mice. Bioscience Biotechnology and Biochemistry, 65(12), 2735-2740. doi:10.1271/bbb.65.2735 
Ohyama, K., Nogusa, Y., Shinoda, K., Suzuki, K., Bannai, M., \& Kajimura, S. (2016). A Synergistic Antiobesity Effect by a Combination of Capsinoids and Cold Temperature Through Promoting Beige Adipocyte Biogenesis. Diabetes, 65(5), 1410-1423. doi:10.2337/db15-0662

Ono, K., Tsukamoto-Yasui, M., Hara-Kimura, Y., Inoue, N., Nogusa, Y., Okabe, Y., . . Kato, F. (2011). Intragastric administration of capsiate, a transient receptor potential channel agonist, triggers thermogenic sympathetic responses. Journal of Applied Physiology, 110(3), 789-798. doi:10.1152/japplphysiol.00128.2010

Oteiza, P. I., Fraga, C. G., Mills, D. A., \& Taft, D. H. (2018). Flavonoids and the gastrointestinal tract: Local and systemic effects. Molecular Aspects of Medicine, 61, 41-49. doi:https://doi.org/10.1016/j.mam.2018.01.001

Otton, R., Bolin, A. P., Ferreira, L. T., Marinovic, M. P., Rocha, A. L. S., \& Mori, M. A. (2018). Polyphenol-rich green tea extract improves adipose tissue metabolism by down-regulating miR-335 expression and mitigating insulin resistance and inflammation. Journal of Nutritional Biochemistry, 57, 170-179. doi:10.1016/j.jnutbio.2018.03.024

Ouellet, V., Routhier-Labadie, A., Bellemare, W., Lakhal-Chaieb, L., Turcotte, E., Carpentier, A. C., \& Richard, D. (2011). Outdoor temperature, age, sex, body mass index, and diabetic status determine the prevalence, mass, and glucose-uptake activity of 18F-FDG-detected BAT in humans. Journal of Clinical Endocrinology and Metabolism, 96(1), 192-199. doi:10.1210/jc.2010-0989

Palacios-González, B., Vargas-Castillo, A., Velázquez-Villegas, L. A., Vasquez-Reyes, S., López, P., Noriega, L. G., ... \& Zarain-Herzberg, A. (2019). Genistein increases the thermogenic program of subcutaneous WAT and increases energy expenditure in mice. The Journal of nutritional biochemistry, 68, 59-68.

Park, A., Kim, W. K., \& Bae, K. H. (2014). Distinction of white, beige and brown adipocytes derived from mesenchymal stem cells. World Journal of Stem Cells, 6(1), 33-42. doi:10.4252/wjsc.v6.i1.33

Parkar, S. G., Trower, T. M., \& Stevenson, D. E. (2013). Fecal microbial metabolism of polyphenols and its effects on human gut microbiota. Anaerobe, 23, 12-19. doi:10.1016/j.anaerobe.2013.07.009

Pereira, D., Valentão, P., Pereira, J., \& Andrade, P. (2009). Phenolics: From Chemistry to Biology. Molecules, 14(6), 2202-2211. doi:10.3390/molecules 14062202

Perez-Jimenez, J., Fezeu L., Touvier M., Arnault N., Manach C., Hercberg S., Galan P., Scalbert A. (2011) Dietary intake of 337 polyphenols in French adults. The American journal of clinical nutrition, 93(6), 1220-1228. doi: 10.3945/ajen.110.007096.

Pinent, M., Blay, M., Serrano, J., \& Ardevol, A. (2017). Effects of flavanols on the enteroendocrine system: Repercussions on food intake. Critical Reviews in Food Science and Nutrition, 57(2), 326-334. doi:10.1080/10408398.2013.871221

Price, N. L., Gomes, A. P., Ling, A. J., Duarte, F. V., Martin-Montalvo, A., North, B. J., . . Sinclair, D. A. (2012). SIRT1 is required for AMPK activation and the beneficial effects of resveratrol on mitochondrial function. Cell Metabolism, 15(5), 675-690. doi:10.1016/j.cmet.2012.04.003

Qiang, L., Wang, L., Kon, N., Zhao, W., Lee, S., Zhang, Y., . . Accili, D. (2012). Brown Remodeling of White Adipose Tissue by SirT1-Dependent Deacetylation of Ppary. Cell, 150(3), 620-632. doi:https://doi.org/10.1016/j.cell.2012.06.027

Reynes, B., Palou, M., Rodriguez, A. M., \& Palou, A. (2018). Regulation of Adaptive Thermogenesis 
and Browning by Prebiotics and Postbiotics. Frontiers in Physiology, 9, 1908.

doi:10.3389/fphys.2018.01908

Ridaura, V. K., Faith, J. J., Rey, F. E., Cheng, J., Duncan, A. E., Kau, A. L., . . Gordon, J. I. (2013).

Gut microbiota from twins discordant for obesity modulate metabolism in mice. Science, 341(6150), 1241214. doi:10.1126/science.1241214

Robidoux, J., Cao, W., Quan, H., Daniel, K. W., Moukdar, F., Bai, X., . . Collins, S. (2005). Selective activation of mitogen-activated protein (MAP) kinase kinase 3 and p38alpha MAP kinase is essential for cyclic AMP-dependent UCP1 expression in adipocytes. Molecular and Cellular Biology, 25(13), 5466-5479. doi:10.1128/mcb.25.13.5466-5479.2005

Rodriguez Lanzi, C., Perdicaro, D., Bottini, R., Miatello, R., Oteiza, P., \& Prieto, M. V. (2017). Grape pomace extract, rich in polyphenols, stimulate the emergence of brown-like cells in white adipose tissue in spontaneously hypertensive rats and in 3T3-L1 adipocytes. Free Radical Biology and Medicine, 108, S83. doi:10.1016/j.freeradbiomed.2017.04.276

Rodriguez Lanzi, C., Perdicaro, D. J., Landa, M. S., Fontana, A., Antoniolli, A., Miatello, R. M., . . Vazquez Prieto, M. A. (2018). Grape pomace extract induced beige cells in white adipose tissue from rats and in 3T3-L1 adipocytes. Journal of Nutritional Biochemistry, 56, 224-233. doi:10.1016/j.jnutbio.2018.03.001

Rosell, M., Kaforou, M., Frontini, A., Okolo, A., Chan, Y. W., Nikolopoulou, E., . . Christian, M. (2014). Brown and white adipose tissues: intrinsic differences in gene expression and response to cold exposure in mice. American Journal of Physiology Endocrinology and Metabolism, 306(8), E945-964. doi:10.1152/ajpendo.00473.2013

Sahuri-Arisoylu, M., Brody, L. P., Parkinson, J. R., Parkes, H., Navaratnam, N., Miller, A. D., . . Bell, J. D. (2016). Reprogramming of hepatic fat accumulation and 'browning' of adipose tissue by the short-chain fatty acid acetate. International Journal of Obesity, 40, 955. doi:10.1038/ijo.2016.23

Scalbert A., Johnson I.T., Saltmarsh M. (2005). Polyphenols: antioxidants and beyond. American Journal of Clinical Nutrition,81(1 Suppl):215S-217S. doi: 10.1093/ajen/81.1.215S.

Scheja L. \& Heeren J. (2016). Metabolic interplay between white, beige, brown adipo

Seale P., Conroe H. M., Estall J., Kajimura S., Frontini A., Ishibashi J., Cohen P., Cinti S., Spiegelman B. M. (2011). Prdm16 determines the thermogenic program of subcutaneous white adipose tissue in mice. Journal of Clinical Investigation, 121, 53-56. doi: 10.1172/JCI44271.

Seale, P., Kajimura, S., Yang, W., Chin, S., Rohas, L. M., Uldry, M., . . Spiegelman, B. M. (2007). Transcriptional control of brown fat determination by PRDM16. Cell Metabolism, 6(1), 38-54. doi:10.1016/j.cmet.2007.06.001

Shimasaki, T., Masaki, T., Mitsutomi, K., Ueno, D., Gotoh, K., Chiba, S., . . Yoshimatsu, H. (2013). The dipeptidyl peptidase-4 inhibitor des-fluoro-sitagliptin regulates brown adipose tissue uncoupling protein levels in mice with diet-induced obesity. PLoS One, 8(5), e63626. doi:10.1371/journal.pone.0063626

Shixian, Q., VanCrey, B., Shi, J., Kakuda, Y., \& Jiang, Y. (2006). Green tea extract thermogenesisinduced weight loss by epigallocatechin gallate inhibition of catechol-O-methyltransferase. Journal of Medicinal Food, 9(4), 451-458. doi:10.1089/jmf.2006.9.451

Silvester, A. J., Aseer, K. R., \& Yun, J. W. (2019). Dietary polyphenols and their roles in fat browning. Journal of Nutritional Biochemistry, 64, 1-12. doi:10.1016/j.jnutbio.2018.09.028

Singh, R. K., Chang, H. W., Yan, D., Lee, K. M., Ucmak, D., Wong, K., . . Liao, W. (2017). Influence 
of diet on the gut microbiome and implications for human health. Journal of Translational Medicine, 15(1), 73. doi:10.1186/s12967-017-1175-y

Su, S., Guntur A. R., Nguyen D. C., Fakory, S. S., Doucette, C. C., Leech, C., ... Brown, A. C. (2018). A renewable source of human beige adipocytes for development of therapies to treat metabolic syndrome. Cell Reports, 25(11), 3215-3228.

Tachibana, H., Koga, K., Fujimura, Y., \& Yamada, K. (2004). A receptor for green tea polyphenol EGCG. Nature Structural \& Molecular Biology, 11(4), 380-381. doi:10.1038/nsmb743

Tamura, Y., Iwasaki, Y., Narukawa, M., \& Watanabe, T. (2012). Ingestion of cinnamaldehyde, a TRPA1 agonist, reduces visceral fats in mice fed a high-fat and high-sucrose diet. Journal of Nutritional Science and Vitaminology, 58(1), 9-13.

Tennen, R. I., Michishita-Kioi, E., \& Chua, K. F. (2012). Finding a target for resveratrol. Cell, 148(3), 387-389. doi:10.1016/j.cell.2012.01.032

Tews, D., \& Wabitsch, M. (2011). Renaissance of brown adipose tissue. Hormone Research in Paediatrics, 75(4), 231-239. doi:10.1159/000324806

Tiraby C, Tavernier G, Lefort C, Larrouy D, Bouillaud F, Ricquier D, \& Langin D. (2003). Acquirement of brown fat cell features by human white adipocytes. Journal of Biological Chemistry, 278(35), 33370-33376.

Tsuda, T. (2015). Possible abilities of dietary factors to prevent and treat diabetes via the stimulation of glucagon-like peptide-1 secretion. Molecular Nutrition \& Food Research, 59(7), 1264-1273. doi:10.1002/mnfr.201400871

Valdes, L., Cuervo, A., Salazar, N., Ruas-Madiedo, P., Gueimonde, M., \& Gonzalez, S. (2015). The relationship between phenolic compounds from diet and microbiota: impact on human health. Food \& Function, 6(8), 2424-2439. doi:10.1039/c5fo00322a

van Dam, A. D., Kooijman, S., Schilperoort, M., Rensen, P. C., \& Boon, M. R. (2015). Regulation of brown fat by AMP-activated protein kinase. Trends in Molecular Medicine, 21(9), 571-579. doi:10.1016/j.molmed.2015.07.003

van Duynhoven, J., Vaughan, E. E., Jacobs, D. M., Kemperman, R. A., van Velzen, E. J., Gross, G., . . Van de Wiele, T. (2011). Metabolic fate of polyphenols in the human superorganism. Proceedings of the National Academy of Sciences of the United States of America, 108 Suppl 1, 4531-4538. doi:10.1073/pnas.1000098107

van Marken Lichtenbelt, W. D., Vanhommerig, J. W., Smulders, N. M., Drossaerts, J. M., Kemerink, G. J., Bouvy, N. D., . . Teule, G. J. (2009). Cold-activated brown adipose tissue in healthy men. New England Journal of Medicine, 360(15), 1500-1508. doi:10.1056/NEJMoa0808718

Vegiopoulos, A., Muller-Decker, K., Strzoda, D., Schmitt, I., Chichelnitskiy, E., Ostertag, A., ... Herzig, S. (2010). Cyclooxygenase-2 controls energy homeostasis in mice by de novo recruitment of brown adipocytes. Science, 328(5982), 1158-1161. doi:10.1126/science. 1186034

Vila-Bedmar, R., Lorenzo, M., \& Fernández-Veledo, S. (2010). Adenosine 5'-MonophosphateActivated Protein Kinase-Mammalian Target of Rapamycin Cross Talk Regulates Brown Adipocyte Differentiation. Endocrinology, 151(3), 980-992. doi:10.1210/en.2009-0810

Villanueva, C. J., Vergnes, L., Wang, J., Drew, B. G., Hong, C., Tu, Y., . . Tontonoz, P. (2013). Adipose subtype-selective recruitment of TLE3 or Prdm16 by PPARgamma specifies lipid storage versus thermogenic gene programs. Cell Metabolism, 17(3), 423-435. doi:10.1016/j.cmet.2013.01.016 
Wang, P., Li, D., Ke, W., Liang, D., Hu, X., \& Chen, F. (2019). Resveratrol-induced gut microbiota reduces obesity in high-fat diet-fed mice. International Journal of Obesity. doi:10.1038/s41366-019-0332-1

Wang, S., Liang, X., Yang, Q., Fu, X., Rogers, C. J., Zhu, M., . . Du, M. (2015). Resveratrol induces brown-like adipocyte formation in white fat through activation of AMP-activated protein kinase (AMPK) alpha1. International Journal of Obesity (2005), 39(6), 967-976. doi:10.1038/ijo.2015.23

Wang, S., Moustaid-Moussa, N., Chen, L., Mo, H., Shastri, A., Su, R., . . Shen, C. L. (2014). Novel insights of dietary polyphenols and obesity. Journal of Nutritional Biochemistry, 25(1), 1-18. doi:10.1016/j.jnutbio.2013.09.001

Wang, W., \& Seale, P. (2016). Control of brown and beige fat development. Nature Reviews: Molecular Cell Biology, 17(11), 691-702. doi:10.1038/nrm.2016.96

Wang, Z., Hu, J., Hamzah, S. S., Ge, S., Lin, Y., Zheng, B., . . Lin, S. (2019). n-Butanol Extract of Lotus Seeds Exerts Antiobesity Effects in 3T3-L1 Preadipocytes and High-Fat Diet-Fed Mice via Activating Adenosine Monophosphate-Activated Protein Kinase. Journal of Agricultural and Food Chemistry, 67(4), 1092-1103. doi:10.1021/acs.jafc.8b05281

Woo, M. N., Jeon, S. M., Shin, Y. C., Lee, M. K., Kang, M. A., \& Choi, M. S. (2009). Anti-obese property of fucoxanthin is partly mediated by altering lipid-regulating enzymes and uncoupling proteins of visceral adipose tissue in mice. Molecular nutrition \& food research, 53(12), 1603-1611.

Wood Dos Santos, T., Cristina Pereira, Q., Teixeira, L., Gambero, A., J, A. V., \& Lima Ribeiro, M. (2018). Effects of Polyphenols on Thermogenesis and Mitochondrial Biogenesis. International Journal of Molecular Sciences, 19(9). doi:10.3390/ijms19092757

Wu, J., Cohen, P., \& Spiegelman, B. M. (2013). Adaptive thermogenesis in adipocytes: is beige the new brown? Genes \& Development, 27(3), 234-250. doi:10.1101/gad.211649.112

Wu, J., Jun, H., \& McDermott, J. R. (2015). Formation and activation of thermogenic fat. Trends in Genetics, 31(5), 232-238. doi:10.1016/j.tig.2015.03.003

Xing, T., Kang, Y., Xu, X., Wang, B., Du, M., \& Zhu, M. J. (2018). Raspberry Supplementation Improves Insulin Signaling and Promotes Brown-Like Adipocyte Development in White Adipose Tissue of Obese Mice. Molecular Nutrition \& Food Research, 62(5). doi:10.1002/mnfr.201701035

Xue, B., Xie, J., Huang, J., Chen, L., Gao, L., Ou, S., . . Peng, X. (2016). Plant polyphenols alter a pathway of energy metabolism by inhibiting fecal Bacteroidetes and Firmicutes in vitro. Food \& Function, 7(3), 1501-1507. doi:10.1039/c5fo01438g

Yamashita, Y., Wang, L., Wang, L., Tanaka, Y., Zhang, T., \& Ashida, H. (2014). Oolong, black and puerh tea suppresses adiposity in mice via activation of AMP-activated protein kinase. Food \& Function, 5(10), 2420-2429. doi:10.1039/c4fo00095a

Yang, F., Xiao, X., Cheng, W., Yang, W., Yu, P., Song, Z., . . Zheng, J. (2015). Structural mechanism underlying capsaicin binding and activation of the TRPV1 ion channel. Nature Chemical Biology, 11(7), 518-524. doi:10.1038/nchembio.1835

Yuan, X., Wei, G., You, Y., Huang, Y., Lee, H. J., Dong, M., . . Jin, W. (2017). Rutin ameliorates obesity through brown fat activation. FASEB Journal, 31(1), 333-345. doi:10.1096/fj.201600459RR

Zhang, J., Wu, H., Ma, S., Jing, F., Yu, C., Gao, L., \& Zhao, J. (2018). Transcription regulators and 
hormones involved in the development of brown fat and white fat browning: transcriptional and hormonal control of brown/beige fat development. Physiological Research, 67(3), 347362. doi: 10.33549 /physiolres. 933650

Zhang, X., Zhang, Q. X., Wang, X., Zhang, L., Qu, W., Bao, B., . . Liu, J. (2016). Dietary luteolin activates browning and thermogenesis in mice through an AMPK/PGC1alpha pathwaymediated mechanism. International Journal of Obesity (2005), 40(12), 1841-1849.

doi:10.1038/ijo.2016.108

Zhang, Y., Li, R., Meng, Y., Li, S., Donelan, W., Zhao, Y., . . Tang, D. (2014). Irisin stimulates browning of white adipocytes through mitogen-activated protein kinase p38 MAP kinase and ERK MAP kinase signaling. Diabetes, 63(2), 514-525. doi:10.2337/db13-1106

Zhang, Y., Xie, C., Wang, H., Foss, R. M., Clare, M., George, E. V., . . Yang, L. J. (2016). Irisin exerts dual effects on browning and adipogenesis of human white adipocytes. American Journal of Physiology Endocrinology and Metabolism, 311(2), E530-541. doi:10.1152/ajpendo.00094.2016

Zhao, L., Zhang, Q., Ma, W., Tian, F., Shen, H., \& Zhou, M. (2017). A combination of quercetin and resveratrol reduces obesity in high-fat diet-fed rats by modulation of gut microbiota. Food \& Function, 8(12), 4644-4656. doi:10.1039/c7fo01383c

Zhou, Q., Chen, K., Liu, P., Gao, Y., Zou, D., Deng, H., . . Mi, M. (2015). Dihydromyricetin stimulates irisin secretion partially via the PGC1alpha pathway. Molecular and Cellular Endocrinology, 412, 349-357. doi:10.1016/j.mce.2015.05.036

Zou, T., Chen, D., Yang, Q., Wang, B., Zhu, M. J., Nathanielsz, P. W., \& Du, M. (2017). Resveratrol supplementation of high-fat diet-fed pregnant mice promotes brown and beige adipocyte development and prevents obesity in male offspring. Journal of Physiology, 595(5), 1547 1562. doi:10.1113/jp273478 
Figure 1

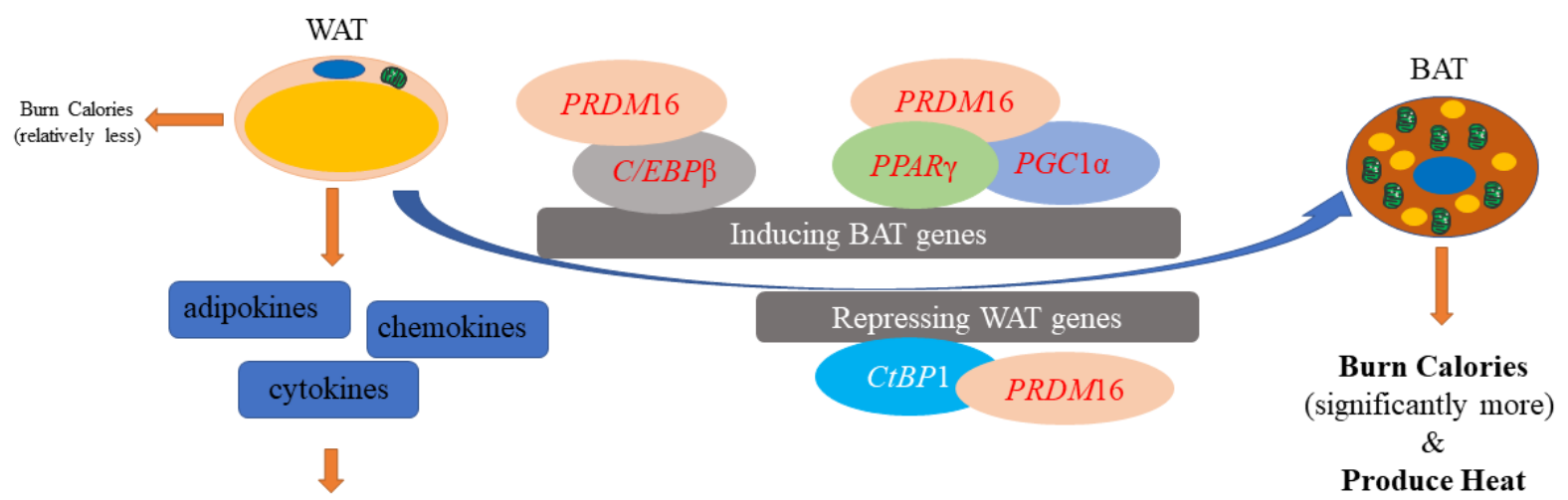

WAT inflammation 
Figure 2

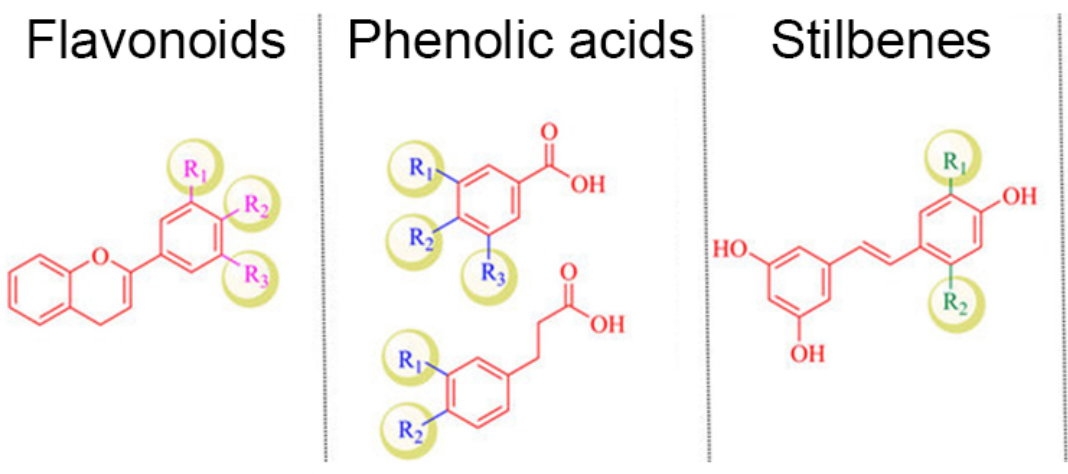

Lignans

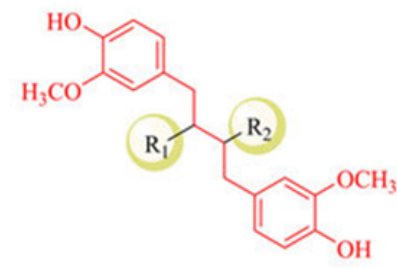


Figure 3

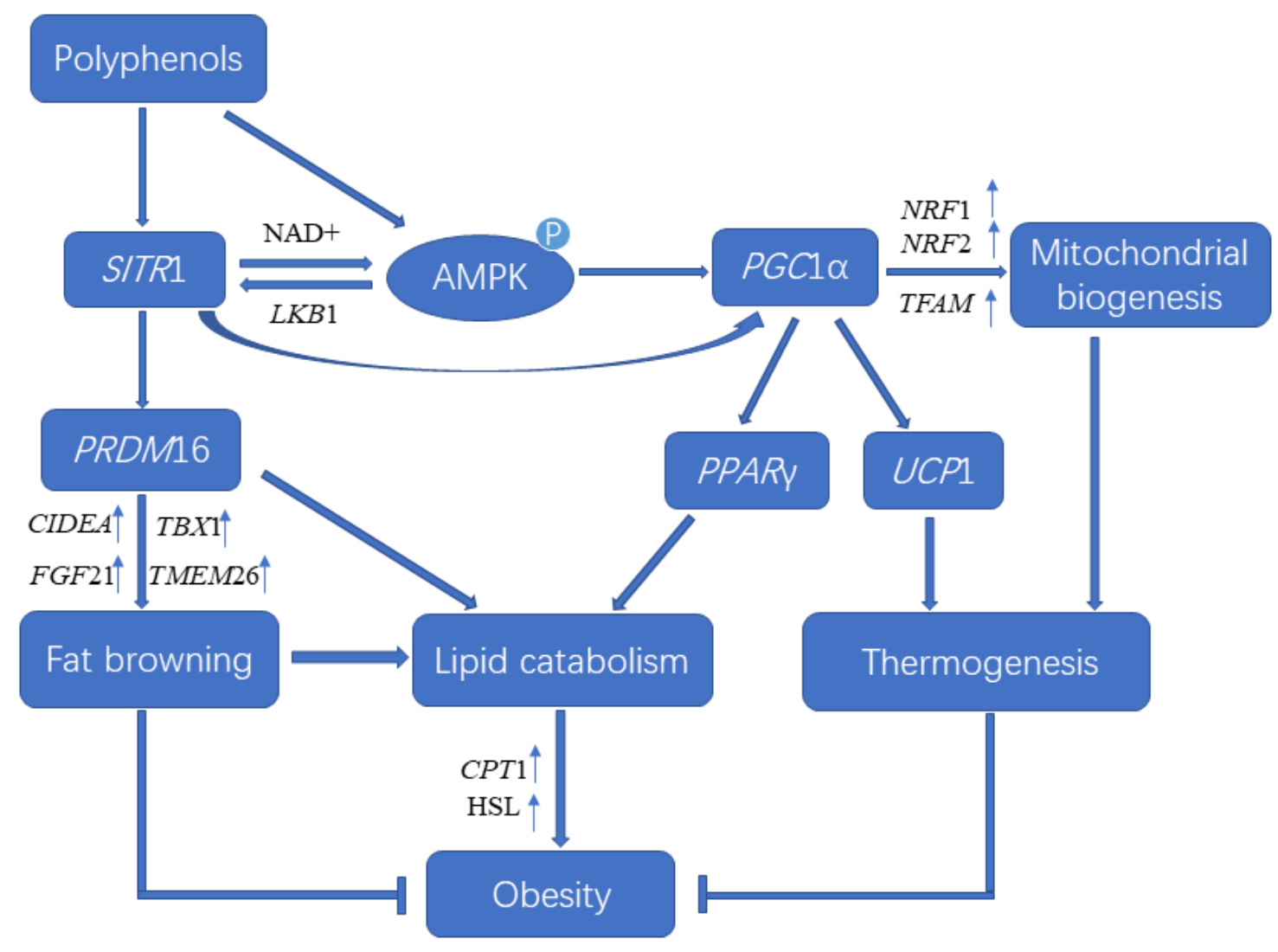


Figure 4

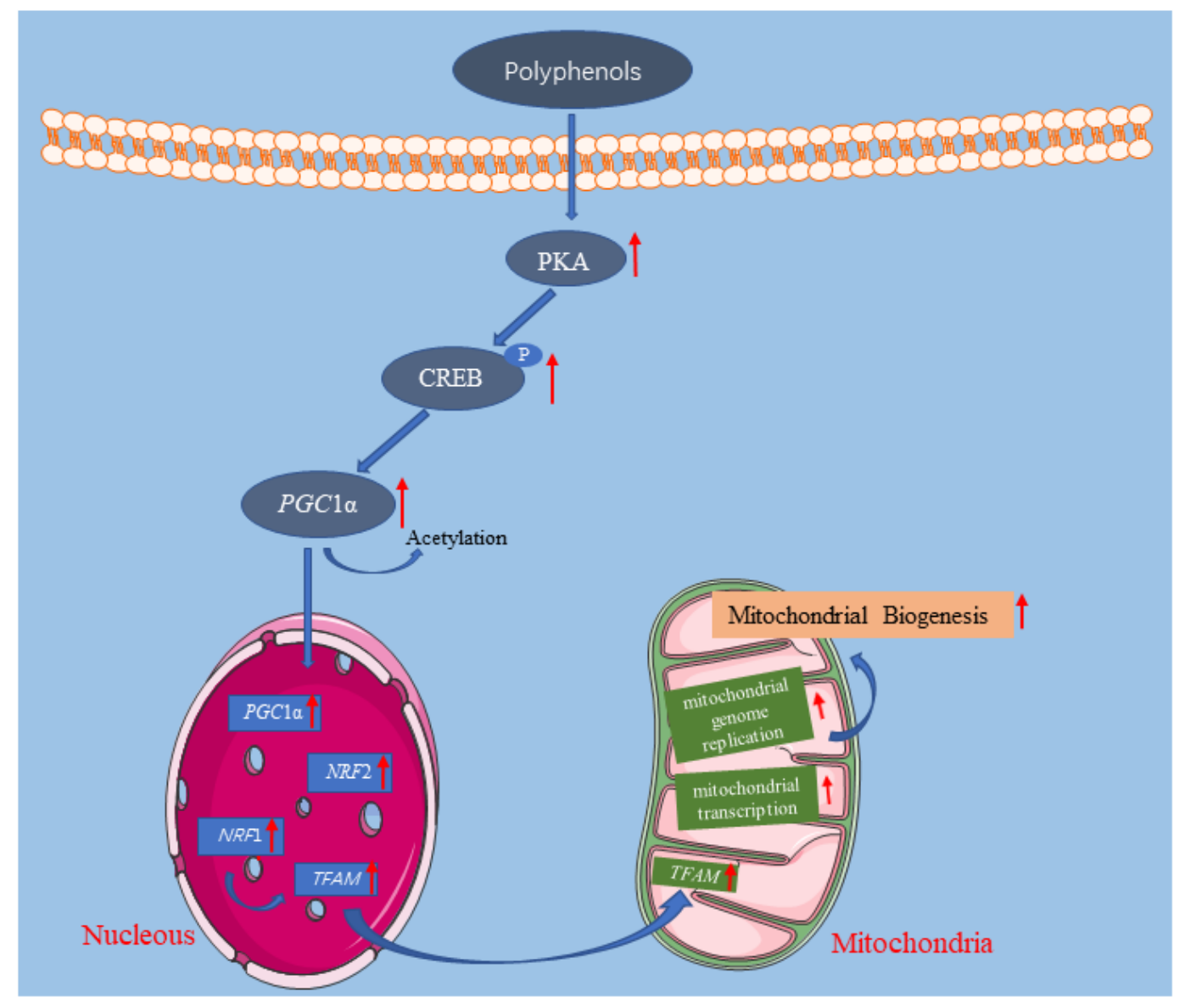


Figure 5

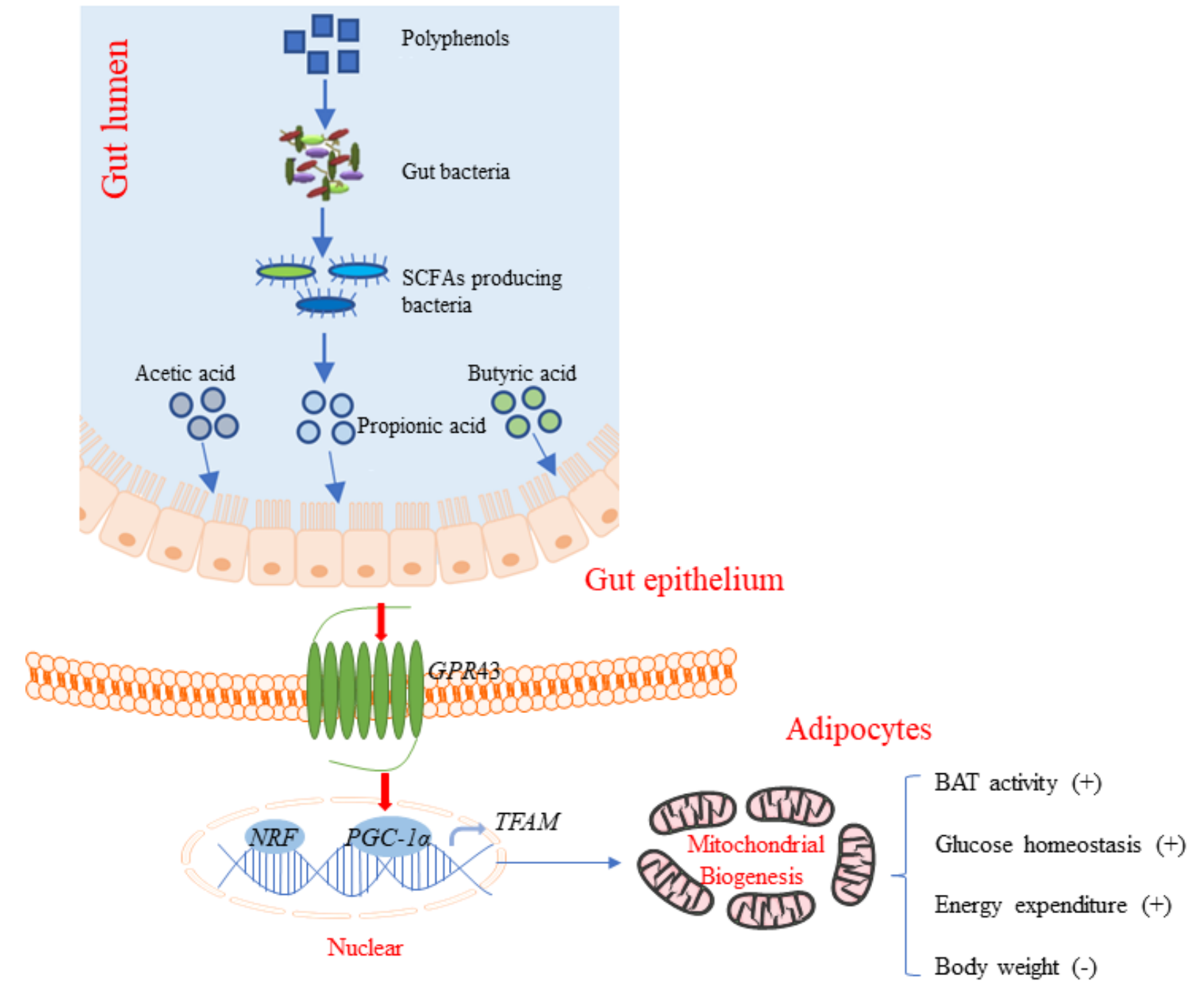


Table 1 The main location and characteristics of different adipose tissues in mammals.

\begin{tabular}{|c|c|c|c|c|}
\hline \multicolumn{2}{|c|}{ Adipose tissues } & WAT & BAT & Beige AT \\
\hline \multirow[b]{2}{*}{ Localization } & Mice & $\begin{array}{l}\text { Omental, Perigonadal, Intramuscular, } \\
\text { Retroperitoneal, Mesenteric, Inguinal }\end{array}$ & Interscapular, Perirenal & Subcutaneous WAT \\
\hline & Humans & $\begin{array}{l}\text { Epicardia, Retroperitoneal, Gluteal, Omental, } \\
\text { Mesenteric, Gonadal, Subcutaneous } \\
\text { abdominal, Femoral }\end{array}$ & $\begin{array}{l}\text { Supraclavicular, Paravertebral, } \\
\text { Suprarenal, }\end{array}$ & Supraclavicular \\
\hline \multicolumn{2}{|c|}{ Cellular composition } & $\begin{array}{l}\text { Single large lipid droplet; } \\
\text { Few mitochondria; } \\
\text { Flattened peripheral nucleus }\end{array}$ & $\begin{array}{l}\text { Multiple small lipid droplets; } \\
\text { A large of mitochondria; } \\
\text { Oval central nucleus }\end{array}$ & $\begin{array}{l}\text { Small lipid droplets; } \\
\text { Mitochondria appear with } \\
\text { stimulation }\end{array}$ \\
\hline \multicolumn{2}{|l|}{ Function } & Energy storage & $\begin{array}{l}\text { Energy consumption and } \\
\text { non-shivering thermogenesis }\end{array}$ & Thermogenesis potential \\
\hline
\end{tabular}


Table 2 Dietary polyphenols function as bioactive substances promoting browning of white fat

\begin{tabular}{|c|c|c|c|c|c|c|c|}
\hline $\begin{array}{l}\text { Polyphenols/ } \\
\text { Polyphenol- } \\
\text { rich foods }\end{array}$ & $\begin{array}{l}\text { Categories/ } \\
\text { Identified polyphenols }\end{array}$ & Structure formula & $\begin{array}{c}\text { Experimental } \\
\text { models }\end{array}$ & Dosage & Duration & Effects & References \\
\hline $\begin{array}{l}\text { trans- } \\
\text { Cinnamic } \\
\text { acid }\end{array}$ & Phenolic acid & & $\begin{array}{c}\text { 3T3-L1 } \\
\text { adipocytes }\end{array}$ & $\begin{array}{c}10,50,100 \\
200 \mu \mathrm{M}\end{array}$ & 4-8days & $\begin{array}{c}U C P 1 \uparrow, P R D M 16 \uparrow, P G C 1 \alpha \uparrow, \\
\mathrm{CD} 137 \uparrow, C I D E A \uparrow, C I T E D 1 \uparrow, T B X 1 \uparrow, \\
T M E M 26 \uparrow, \mathrm{p}-\mathrm{AMPK} \uparrow, \text { and } \beta 3-\mathrm{AR} \uparrow\end{array}$ & $\begin{array}{l}\text { Kang, Mukherjee, \& } \\
\text { Yun, } 2019\end{array}$ \\
\hline \multirow{2}{*}{ Capsaicin } & & & $\begin{array}{l}\text { Male } \mathrm{C} 57 \mathrm{BL} / 6 \mathrm{~J} \\
\text { mice }\end{array}$ & $\begin{array}{c}0.3 \% \\
\text { capsinoids }\end{array}$ & 4 weeks & $\begin{array}{c}\text { Vagal afferent pathways } \uparrow, \\
\text { Adrenergic pathways } \uparrow\end{array}$ & Ohyama et al., 2016; \\
\hline & & & $\begin{array}{c}\text { 3T3-L1 } \\
\text { preadipocytes }\end{array}$ & $0.1-100 \mu \mathrm{M}$ & 8 days & $\begin{array}{c}U C P 1 \uparrow, P G C 1 \alpha \uparrow, P R D M 16 \uparrow, \\
D I O 2 \uparrow, P P A R \alpha \uparrow, F O X C 2 \uparrow\end{array}$ & Baboota et al., 2014 \\
\hline Chrysin & Flavonoids & & $\begin{array}{c}\text { 3T3-L1 } \\
\text { adipocytes }\end{array}$ & $50 \mu \mathrm{M}$ & 6-8days & $\begin{array}{c}\text { p-AMPK } \uparrow, P P A R \alpha \uparrow, P G C 1 \alpha \uparrow, \\
C I D E A \uparrow, P R D M 16 \uparrow, U C P 1 \uparrow\end{array}$ & $\begin{array}{c}\text { Choi J, \& Yun J, } \\
2019\end{array}$ \\
\hline Ellagic acid & Phenolic acid & & Male SD rats & $\begin{array}{l}10 \text { or } 30 \\
\mathrm{mg} / \mathrm{kg} / \mathrm{d}\end{array}$ & 24 weeks & $\begin{array}{c}U C P 1 \uparrow, P R D M 16 \uparrow, C I D E A \uparrow, \\
P G C 1 \alpha \uparrow, C D 137 \uparrow, T M E M 26 \uparrow, T F A M \uparrow\end{array}$ & Wang et al., 2019 \\
\hline Eriodictyol & Flavonoids & & $\begin{array}{l}\text { Male } \mathrm{C} 57 \mathrm{BL} / 6 \mathrm{~N} \\
\text { mice }\end{array}$ & $\begin{array}{l}0.005 \%(\mathrm{w} / \mathrm{w}) \\
\text { eriodictyol }\end{array}$ & 16 weeks & 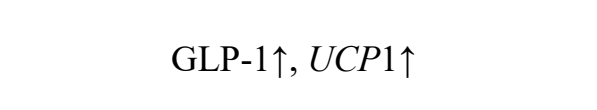 & Kwon \& Choi, 2019 \\
\hline Gallic acid & Phenolic acid & & C57BL/6 mice & $10 \mathrm{mg} / \mathrm{kg} \mathrm{bw}$ & 9 weeks & AMPK/SIRT1/PGC1 $\alpha$ pathway $\uparrow$ & Doan et al., 2015 \\
\hline
\end{tabular}




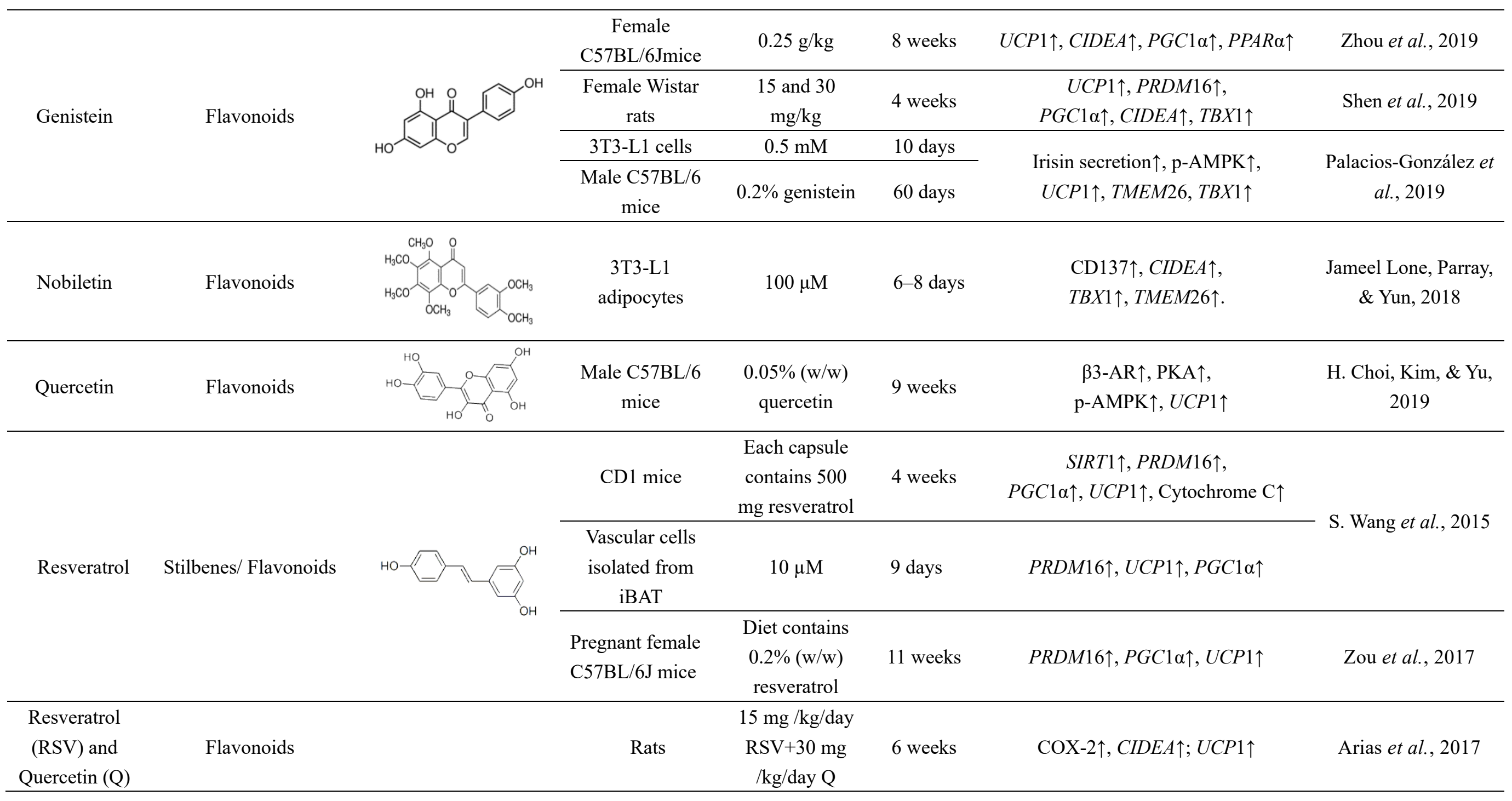




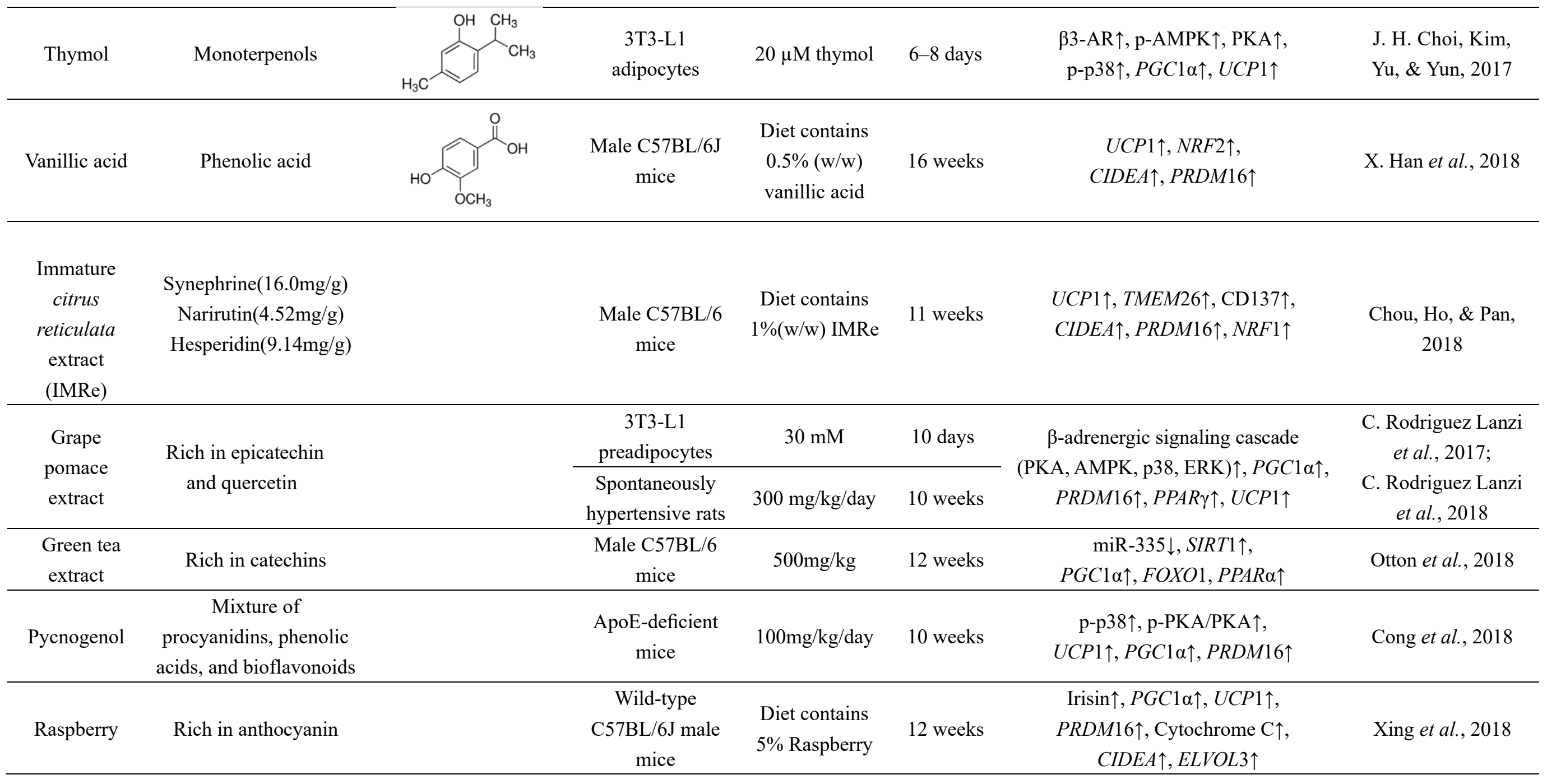


AMPK: AMP-activated protein kinase; $\boldsymbol{\beta 3}$-AR: $\boldsymbol{\beta} 3$-adrenergic receptor; CD137: Tumor necrosis factor receptor superfamily member 9; $\boldsymbol{C I D E A}$ : Cell death-inducing DNA fragmentation factor, alpha subunit-like effector A; CITED1: Cbp/p300-Interacting Transactivator 1; COX-1: Cyclooxygenase 1; COX-2: Cyclooxygenase 2; DIO2, Iodothyronine Deiodinase 2; ELVOL3:, ELOVL Fatty Acid Elongase 3; ERK: Extracellular signal-regulated kinases; FOXC2: Forkhead box protein C2; FOXO1: Forkhead box protein O1; GLP-1: Glucagon-like peptide-1; NRF1: Nuclear respiratory factor 1; NRF2: Nuclear respiratory factor 2; p38: p38 mitogen-

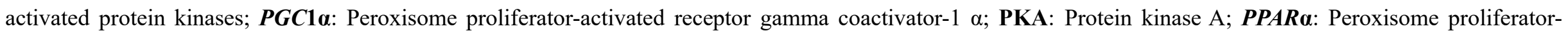
activated receptor $\alpha$; PPAR $\gamma$ : Peroxisome proliferator-activated receptor $\gamma ; \boldsymbol{P R D M 1 6 :}$ PR domain-containing 16; SIRT1: Sirtuin 1; TBX1: T-box protein 1; TFAM: Mitochondrial transcription factor A; TMEM26: Transmembrane protein 26; UCP1: Uncoupling protein 1; 